\title{
Recent advances on silica-based nanostructures in photocatalysis
}

\author{
Heng Wang, Qian Tang, Zhen Chen, Tao Li and Jingyu Wang*
}

\begin{abstract}
Development of highly efficient photocatalysts has emerged as a research hotspot because of their crucial role in affecting the conversion efficiency of solar energy for applications in resource exploitation and environmental purification. The photocatalytic performance of the photocatalysts basically depends on the behaviors of light absorption, charge generation and separation, surface property and structural stability. Owing to its unique advantages (high surface area, tunable porosity, modifiable surface), porous silica provides an interesting platform to construct well-defined nanostructures such as core-shell, yolk-shell and other specific structures which effectively improved one or more of the above behaviors for photocatalysis. Typically, the structure with hollow morphology favors the light scattering and enlargement of surface area, while coating or binding with silica can modify the surface property of a photocatalyst to enhance the surface adsorption of reactants and physicochemical stability of catalysts. This review discusses the recent advances in the design, synthesis, formation mechanism of well-defined silica-based nanostructures, and the achievements of desired physicochemical properties for regulating the photocatalytic performance.
\end{abstract}

Keywords: composite photocatalyst, silica, structural design, environment, energy

\section{INTRODUCTION}

The increasing consumption of fossil fuels and emission of hazardous pollutants have brought about serious energy and environmental issues which exert great pressure on the social development and human survival [1-4]. There is an urgent need to develop effective measures to facilitate the utilization of renewable and environmentally friendly energy sources as well as the purification of en- vironmental pollutants [5-9]. Photocatalytic technique has attracted overwhelming attention since it can realize the conversion of clean and inexhaustible solar energy into valuable chemical forms [10-14]. The whole photocatalytic reactions proceed under relatively green conditions, including $\mathrm{CO}_{2}$ reduction [15-18], hydrogen evolution [19-23], degradation of organic pollutants [24$27]$, and inorganic pollutants removal $[28,29]$.

In recent years, considerable efforts have been made on the construction of heterogeneous composite photocatalysts owing to their potentials in achieving enhanced photocatalytic performance [30-33]. Various composite photocatalysts have been rationally designed and applied in different photocatalytic fields [34]. Although some single-component semiconductor photocatalysts possess excellent properties, there are still certain limitations including agglomeration of nanoparticles (NPs), chemical instability as well as difficulty in recovery and recycling. Moreover, the photocatalytic performance strongly depends on the specific surface area and light absorption ability which can also be improved by the design and assembly of specific structures $[35,36]$. To overcome these shortcomings, versatile strategies have been developed to construct composite structures with well-defined morphology and interface.

Porous silica as a typical porous material has been widely used for the synthesis of many kinds of functional nanomaterials owing to its unique advantages such as high surface area, facile controllability of pore size, low cost, environmental friendliness as well as thermal and mechanical stability [37-39]. Especially, the silica surface can be easily modified with various molecules to benefit the connection with other materials [40,41]. In most cases, the porous silica can be employed as an ideal sa-

Key Laboratory of Materials Chemistry for Energy Conversion and Storage (Ministry of Education), Hubei Key Laboratory of Material Chemistry and Service Failure, School of Chemistry and Chemical Engineering, Huazhong University of Science and Technology, Wuhan 430074, China

* Corresponding author (email: wangjingyu@hust.edu.cn) 
crificial template to realize the structural manipulation of various materials [42]. According to the function of silica, it can serve as the support, coating layer and binding material to construct the well-defined nanostructures. The characteristics of these structures are correlated with the location of silica as well as the choice to retain or remove the silica content [43]. For instance, using porous silica as a core support, the agglomerations of photocatalysts can be greatly restricted to improve the dispersibility $[44,45]$. When the photocatalysts are coated with silica layers, the protective physical barrier will prevent the dissolution and oxidation of the inner catalysts and thus improve their chemical stabilities. Meanwhile, the surface property of the photocatalyst can be modified to enhance the surface adsorption of reactants [46]. Alternatively, the silica sometimes exists as a binding interlayer, which enables the merging of multiple components into one system to bring about synergistic effects $[47,48]$. In addition, the porous silica with regular morphology can also act as a template to fabricate the hollow structures by etching under the alkaline or high temperature conditions, favoring the light scattering and enlargement of surface area $[49,50]$. Therefore, the introduction of porous silica presents an interesting platform to design and construct well-defined nanostructures which can effectively improve one or more of the physicochemical properties for efficient photocatalysis [51].

In this review, we summarize the design, synthesis and formation mechanism of silica-based nanostructures, and the achievements of desired physicochemical properties for regulating the photocatalytic performance. The overview of these main types of silica-based photocatalysts is displayed in Fig. 1. According to the geometric shapes, they can be broadly classified into core-shell structured nanomaterials (CSNs), yolk-shell structured nanomaterials (YSNs) and other specific structures. For each type, silica may serve as the core, outer shell or interlayer, depending on the target of the designed nanostructures. The photocatalytic performance of these well-defined nanostructures has been mainly discussed from the aspects of $\mathrm{CO}_{2}$ reduction, hydrogen production, and degradation of organic pollutants. The advantages and disadvantages of some reported silica-based nanostructures are summarized in Table 1. Theoretically, the photocatalytic reactions are driven by the photogenerated charge carriers which participate in multistep physicochemical processes, including light absorption, charge generation and separation, and surface reactions. Among these factors, the decisive one for the whole photocatalytic process is still unclear so far. One viewpoint is that the

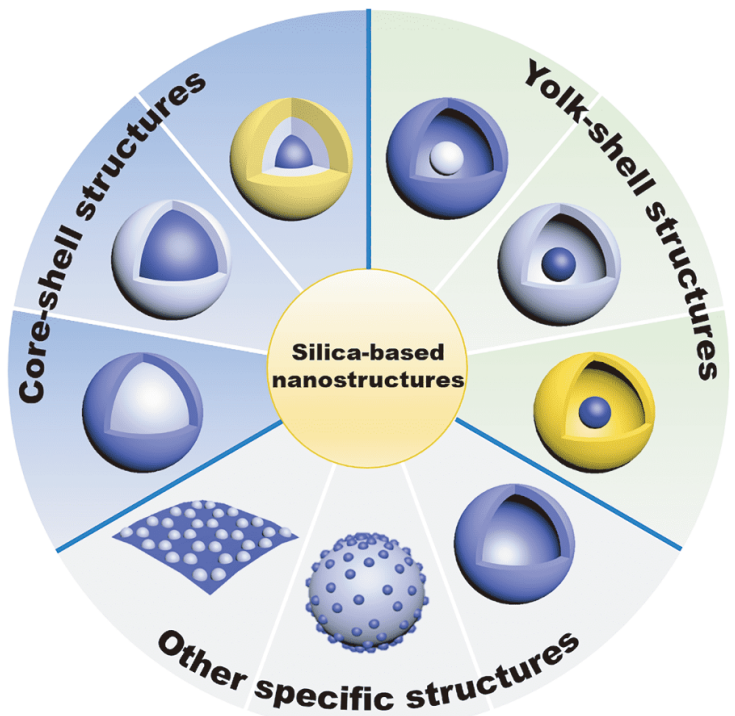

Figure 1 Diagrams of silica-based nanostructures. The grey part represents silica; blue and yellow parts represent other materials.

efficiency of charge utilization in every step determines the overall performance of photocatalysts [52], while some other reports conclude that the decisive factor varies with different photocatalytic mechanisms [53]. For example, the adsorption of pollutants on the surfaces of photocatalysts is usually the rate-determining step for pollutant degradation, so that the photocatalysts with large surface area are preferred. For photocatalytic water splitting, it is widely accepted that surface charge injection is the rate-determining step for the whole process [53]. Through reviewing the recent advances on silicabased nanostructures, we also present a brief conclusion and outlook on the future development. This review may provide new opportunities for the rational design and construction of highly efficient photocatalysts for various applications. Besides, the established relationships between structure and physicochemical properties may also function well for regulating other catalytic performances and be extended to versatile applications.

\section{DESIGN OF CORE-SHELL SILICA-BASED COMPOSITE PHOTOCATALYSTS}

The core-shell morphology is one of the most popular silica-based nanostructures. CSNs provide great opportunities to manipulate core and shell components into a functional system, thus improving one or more behaviors including surface property and structural stability for photocatalysis [54]. Such a well-defined nanostructure can be constructed using porous silica as the support, 
Table 1 Advantages and disadvantages of some reported silica-based nanostructures

\begin{tabular}{|c|c|c|c|}
\hline Silica-based nanostructures & Advantages & Disadvantages & Ref. \\
\hline \multicolumn{4}{|c|}{ I. Core-shell silica-based composite photocatalysts } \\
\hline $\begin{array}{l}\text { Silica-supported core-shell } \\
\text { structure }\end{array}$ & $\begin{array}{l}\text { Promote dispersibility of the photocatalyst } \\
\text { NPs on the outer layer of silica }\end{array}$ & & {$[61,65]$} \\
\hline $\begin{array}{l}\text { Silica-coated core-shell } \\
\text { structure }\end{array}$ & $\begin{array}{l}\text { Protect the photocatalyst core from dissolution or } \\
\text { oxidation to improve the chemical stability; modify } \\
\text { the surface properties to benefit the adsorption and } \\
\text { diffusion of the reactant molecules }\end{array}$ & $\begin{array}{l}\text { Difficult to maintain stability in high- } \\
\text { temperature steam environment or alkaline } \\
\text { media; partly shield the light absorption } \\
\text { and block the active sites of the } \\
\text { photocatalysts by silica coating }\end{array}$ & {$[72,73]$} \\
\hline $\begin{array}{l}\text { Silica-interlayered core-shell } \\
\text { structure }\end{array}$ & $\begin{array}{l}\text { Combine multi-components to generate the } \\
\text { synergistic effect in a photocatalytic system }\end{array}$ & & {$[77,78]$} \\
\hline \multicolumn{4}{|c|}{ II. Yolk-shell silica-based composite photocatalysts } \\
\hline $\begin{array}{l}\text { Silica-supported yolk-shell } \\
\text { structure }\end{array}$ & $\begin{array}{l}\text { Suppress the aggregation of the photocatalyst on the } \\
\text { outer layer; form the hollow morphology to enlarge } \\
\text { specific surface area; enhance light absorption by } \\
\text { multistep reflections in inner hole }\end{array}$ & & {$[86,87]$} \\
\hline Silica-coated yolk-shell structure & $\begin{array}{l}\text { Encapsulate active photocatalyst core in the silica } \\
\text { shell to enhance the stability; improve the adsorption } \\
\text { properties like a molecular-sieving configuration; } \\
\text { enlarge specific surface area and enhance light } \\
\text { absorption by the hollow structure }\end{array}$ & $\begin{array}{l}\text { Involve complex synthetic procedure, } \\
\text { unavoidable template consumption, and } \\
\text { low yield; difficult to completely remove } \\
\text { the silica or precisely adjust the partial } \\
\text { etching of silica }\end{array}$ & {$[89,91]$} \\
\hline $\begin{array}{l}\text { Silica-interlayered yolk-shell } \\
\text { structure }\end{array}$ & $\begin{array}{l}\text { Incorporation of multiple components into a } \\
\text { photocatalytic system; confine the photocatalyst in } \\
\text { the void space to keep the morphology and } \\
\text { dispersibility; improve light utilization by the cavity }\end{array}$ & & {$[94,96]$} \\
\hline \multicolumn{4}{|c|}{ III. Other specific structures of silica-based photocatalysts } \\
\hline Hollow nanospheres & $\begin{array}{l}\text { Improve surface area, adsorption capacity, and light } \\
\text { harvesting ability by the hollow structure }\end{array}$ & $\begin{array}{l}\text { Contain unavoidable template consumption } \\
\text { and increase economic cost }\end{array}$ & {$[101,102]$} \\
\hline Silica-supported NPs & $\begin{array}{c}\text { Promote the dispersion of photocatalyst NPs and } \\
\text { provide more active sites }\end{array}$ & $\begin{array}{l}\text { Difficult to maintain stability in high- } \\
\text { temperature steam environment or alkali } \\
\text { media }\end{array}$ & {$[103,104]$} \\
\hline Silica-decorated nanostructure & $\begin{array}{l}\text { Modify surface property with desired functional } \\
\text { groups; promote intimate contact and charge transfer } \\
\text { between silica and other materials }\end{array}$ & $\begin{array}{l}\text { Partly shield the light absorption and } \\
\text { block the active sites }\end{array}$ & {$[105,106]$} \\
\hline
\end{tabular}

coating layer, as well as binding material owing to its superb properties like physical and chemical stabilities, environmental friendliness and readily availability [55]. The morphology of porous silica can be easily controlled and prepared by the hydrolysis of tetraethyl orthosilicate (TEOS) via the Stöber method [56]. Subsequently, it can be modified by combining with metal oxide $\left(\mathrm{TiO}_{2}, \mathrm{Fe}_{2} \mathrm{O}_{3}\right.$, $\mathrm{Fe}_{3} \mathrm{O}_{4}$, etc.), noble metal (Ag, $\mathrm{Au}$ and $\mathrm{Pt}$ ) and other classes of semiconductors ( $g-\mathrm{C}_{3} \mathrm{~N}_{4}$ and $\mathrm{CdS}$ ) to optimize the surface property and achieve good photocatalytic activity [57]. In silica-based CSNs, porous silica is completely retained in the different locations of composites to regulate the characteristics.

\section{Silica-supported core-shell structure}

In the silica-supported core-shell structure, porous silica is introduced as the core support materials owing to its physicochemical stability, rich surface functional groups and high adsorption capacity, solving the problem of NPs' agglomeration and improving the dispersibility [58,59].
The silica-supported $\mathrm{TiO}_{2}$ composites have been extensively investigated because their physico-chemical properties are superior to that of the naked $\mathrm{TiO}_{2}$ [60]. For example, Ullah and co-workers [61] fabricated $\mathrm{SiO}_{2} @$ $\mathrm{TiO}_{2}$ hybrid particles, which exhibited the enhanced photocatalytic degradation activity of crystal violet as compared with the unsupported $\mathrm{TiO}_{2}$ NPs with similar size. Through simply varying the amount of precursor (TiP), the thickness of the $\mathrm{TiO}_{2}$ shell could be easily controlled to allow better dispersion of titania on the surface and improve the adsorption of pollutants. As a consequence of the combination of the silica core and titania shell, the CSNs showed a beneficial effect on the photocatalytic degradation properties. To further boost the photocatalytic activity of the silica-supported CSNs, noble metal NPs like Au or Ag NPs were deposited to induce the plasmonic energy transfer between the metal and semiconductor [62-64]. Ma et al. [65] fabricated Agdecorated $\mathrm{SiO}_{2} @ \mathrm{TiO}_{2}$ core-shell microspheres $\left(\mathrm{SiO}_{2} @\right.$ $\mathrm{TiO}_{2}-\mathrm{Ag}$ ) using $\mathrm{SiO}_{2}$ as the support (Fig. 2). The results 

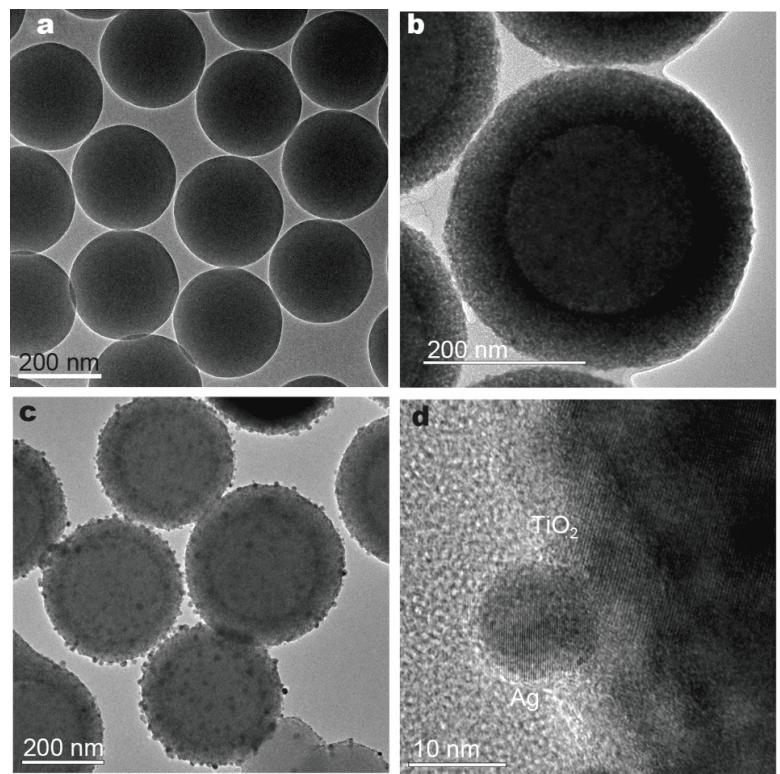

Figure 2 Transmission electron microscopy (TEM) images of (a) $\mathrm{SiO}_{2}$, (b) calcined $\mathrm{SiO}_{2} @ \mathrm{TiO}_{2}$, and (c) deposited Ag NPs on $\mathrm{TiO}_{2}$ surface in $\mathrm{SiO}_{2} @ \mathrm{TiO}_{2}$; (d) high resolution TEM (HRTEM) image of the coated $\mathrm{TiO}_{2}$ and deposited Ag NPs on $\mathrm{SiO}_{2}$. Reprinted with permission from Ref. [65]. Copyright 2017, Elsevier.

suggested that the smooth monodisperse $\mathrm{SiO}_{2}$ spheres with a diameter of $\sim 260 \mathrm{~nm}$ became rough and textured when being covered by the uniform coating layer of $\mathrm{TiO}_{2}$ with the thickness of ca. $55 \mathrm{~nm}$. Subsequently, the Ag NPs with a small size were highly dispersed on the $\mathrm{TiO}_{2}$ surface by the modified Ag-seed-mediated photodeposition route. It was demonstrated that the silica core in the CSNs effectively facilitated the coating of $\mathrm{TiO}_{2}$ layer and the uniform growth of Ag NPs, thus providing more catalytic centers for photocatalytic degradation of methylene blue (MB). Another strategy is to couple silicasupported $\mathrm{TiO}_{2}$ CSNs with other metal oxides for the improvement of photocatalytic performance. For example, Zelekew et al. [66] prepared silica-supported $\mathrm{TiO}_{2} / \mathrm{Ag}_{2} \mathrm{O}$ heterostructured photocatalysts towards the photodegradation of Rhodamine $\mathrm{B}(\mathrm{RhB})$. The enhanced photocatalytic activity was ascribed to many factors, among which the silica support improved the surface property of composite photocatalysts. Titania was covalently attached to the silica surface to realize better dispersion against aggregation, and then facilitated the adsorption of organic molecules on the active sites of photocatalysts. Therefore, the effective separation of electrons and holes was accomplished by the formation of p- $n$ heterostructures between $\mathrm{TiO}_{2}$ and $\mathrm{Ag}_{2} \mathrm{O}$, leading to the enhanced degradation of $\mathrm{RhB}$ under both $\mathrm{UV}$ and visible light irradiations.

The silica core can also be combined with other photocatalyst shells such as $\mathrm{Ta}_{3} \mathrm{~N}_{5}$ [67] and g- $\mathrm{C}_{3} \mathrm{~N}_{4}$ [68] to form core-shell configuration. For instance, Liu et al. [69] further demonstrated that the dispersibilities of $\mathrm{Ta}_{3} \mathrm{~N}_{5}$ / $\mathrm{SiO}_{2}$ core-shell-structured photocatalysts in the solution were well controlled in the presence of silica support, thus showing improved photocatalytic capabilities $\left(5.0 \mu \mathrm{mol} \mathrm{h}^{-1}\right)$ for hydrogen evolution in methanol/water mixture in comparison with the pure $\mathrm{Ta}_{3} \mathrm{~N}_{5}$ powders $\left(1.4 \mu \mathrm{mol} \mathrm{h}{ }^{-1}\right)$. All these studies suggested that the introduction of silica core support in CSNs is an effective approach for the uniform coating of photocatalyst shell, which can realize better surface property of dispersibility for enhancing photocatalytic performance.

\section{Silica-coated core-shell structure}

In the silica-coated core-shell structure, the silica coating can act as a physical barrier to protect the core from dissolution or oxidation to improve the chemical stability [70]. Moreover, it can also modify the surface property by providing mesoporous channels to control the interparticle interactions as well as benefit the adsorption and diffusion of the reactant molecules [71].

For the purpose of photocatalyst cycling, magnetic NPs were always employed as supports in order to overcome the difficulties in the separation and recovery of photocatalysts. However, the inner magnetic core inevitably suffered from the dissolution and oxidation during the photocatalytic reactions. In this regard, coating with a silica layer can effectively protect the magnetic cores and improve the physicochemical stability of the composite photocatalysts. For example, in the core-shell $\mathrm{Fe}_{3} \mathrm{O}_{4} @ \mathrm{SiO}_{2}$ composite, the photocorrosion of $\mathrm{Fe}_{3} \mathrm{O}_{4}$ was suppressed during the photocatalytic oxidation process and the photothermal effect of $\mathrm{Fe}_{3} \mathrm{O}_{4}$ was maintained. This result could be explained by the presence of the protective silica shell, and therefore the composite exhibited superior stability and an activity enhancement of $38.9 \%$ towards photocatalytic NO conversion [72]. Besides the magnetic iron oxides, the protective effect of silica layer can also be introduced to the application of inherently unstable photocatalysts. Yan et al. [73] fabricated the $\mathrm{Au} /$ $\mathrm{BiOCl} @ \mathrm{mSiO}_{2}$ composite which consisted of a $\mathrm{BiOCl}$ core, a protective mesoporous silica shell, and Au NPs onto the surface (Fig. 3a). The mesoporous silica shell inhibited the excessive growth of $\mathrm{BiOCl}$ nanocrystals during the high temperature calcination in the silica framework, and protected the chlorides or Au species against dissolution in the aqueous solution as well. Thus, 
a

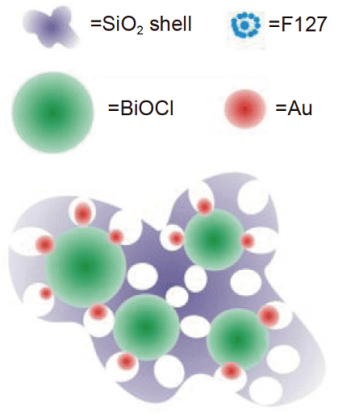

c

- Pollutant

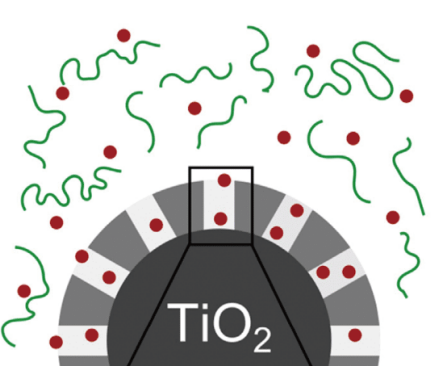

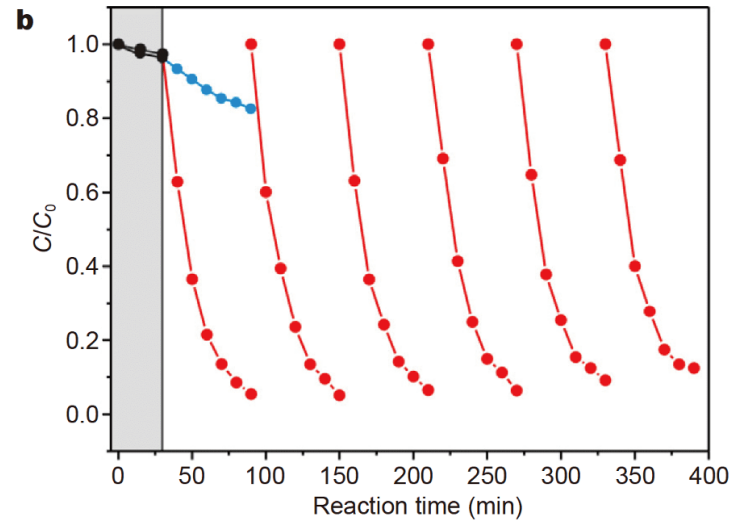

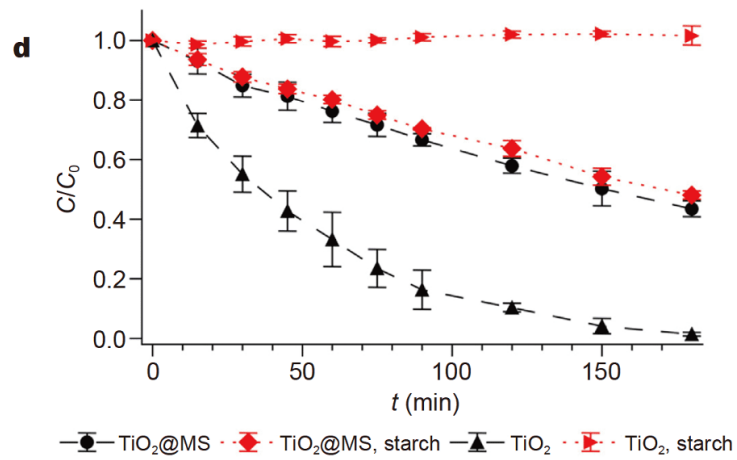

Figure 3 (a) Schematic illustration of $\mathrm{Au} / \mathrm{BiOCl} @ \mathrm{mSiO}_{2}$. (b) Concentration changes of $\mathrm{RhB}$ with $\mathrm{BiOCl} @ \mathrm{mSiO}{ }_{2}$ and $\mathrm{Au} / \mathrm{BiOCl}_{\mathrm{mSiO}}$ photocatalysts in the dark $(30 \mathrm{~min})$ and under visible light $(\lambda>420 \mathrm{~nm})$, and repeated recycling experiments of Au/BiOCl@mSiO $\mathrm{B}_{2}$. Reprinted with permission from Ref. [73]. Copyright 2015, Elsevier. (c) Schematic illustration of $\mathrm{TiO}_{2} @ M S$. (d) Photocatalytic degradation of RhB in the presence and absence of the starch using $\mathrm{TiO}_{2} @ \mathrm{MS}$ and pure $\mathrm{TiO}_{2}$ under UV light. Reprinted with permission from Ref. [74]. Copyright 2017, Elsevier.

the composite possessed high stability after five repeated recycling photocatalytic experiments (Fig. 3b).

On the other hand, the mesoporous silica shell can also provide mesoporous channels and straight pore configuration on the surface of photocatalysts. Such surface modification benefits the rapid adsorption and diffusion of the reactant molecules, leading to the efficient photocatalysis on the surface reaction sites. More importantly, the tunable porous structure can endow the silica-based CSNs with the possibility for selective photocatalytic decomposition of different types of molecules. Nadrah et al. [74] synthesized mesoporous silica-encapsulated $\mathrm{TiO}_{2}$ NPs $\left(\mathrm{TiO}_{2} @ \mathrm{MS}\right)$. It was found that the silica shell was crucial for the selective degradation of model pollutants and presented a sorption area in the vicinity of the photocatalyst (Fig. 3c). When the starch macromolecules were introduced to the model pollutant $(\mathrm{RhB})$ system, the degradation efficiency of $\mathrm{RhB}$ nearly kept unchanged over the $\mathrm{TiO}_{2} @ \mathrm{MS}$ photocatalyst, while a substantial decrease in the degradation efficiency was observed over bare $\mathrm{TiO}_{2}$ (Fig. 3d). A mixture of mesoporous silica and $\mathrm{TiO}_{2}$ particles also showed similar results with $\mathrm{TiO}_{2}$ alone in the case of no silica shell, which verified the importance of silica coating for the selective degradation of $\mathrm{RhB}$. The results further indicated that the modification of surface property by the silica layer can effectively regulate the adsorption ability of reactant molecules. Giesriegl et al. [75] prepared the titania-silica core-shell photocatalysts and revealed the dominate adsorption effect of the ultrathin silica layer. The optimization of ultra-thin silica shells led to a stark increase in activity for $\mathrm{MB}$ and a decrease for methyl orange. On the basis of these results, it can be concluded that coating the photocatalyst core with a silica layer effectively modified its surface properties to form the stable composite structure as well as regulate the adsorption and diffusion abilities, both of which contributed to the improved photocatalytic performances including stability and activity.

\section{Silica-interlayered core-shell structure}

Significant improvements in photocatalytic performance have been achieved by the introduction of silica core as a support and silica shell as a coating layer in the CSNs. In fact, there are still great challenges in the merging of 
multiple components (e.g., bismuth oxyhalides, metal oxide and noble metal) into one system. Strategies are further extended to design an interlayered core-shell heterostructure, aiming to incorporate multiple components into a photocatalytic system, in which silica was used as a binding material due to its special surface properties such as flexibility and adhesiveness [76]. For example, Meng and Zhang [77] constructed a $\mathrm{Ag} / \mathrm{AgCl}-$ $\mathrm{Bi}_{2} \mathrm{WO}_{6} @ \mathrm{Fe}_{3} \mathrm{O}_{4} @ \mathrm{SiO}_{2}$ core-shell composite structure, in which silica was coated outside the $\mathrm{Fe}_{3} \mathrm{O}_{4}$ core to favor the combination with $\mathrm{Bi}_{2} \mathrm{WO}_{6}$ (Fig. 4a). The acid corrosion and oxidation of $\mathrm{Fe}_{3} \mathrm{O}_{4}$ magnetic nanocores were minimized by the protection of the inert silica interlayer. The incorporation of multiple components into such a well-defined heterostructure brought about the synergistic effect of each component, which effectively improved the separation rate of electron/hole pairs to enhance the photodegradation efficiency, i.e., the rate constants of phenol increased from $2.87 \times 10^{-3}$ to $4.77 \times 10^{-3} \mathrm{~min}^{-1}$. Khan et al. [78] also employed silica as an interlayer to the formation of magnetic $\mathrm{BiOBr} / \mathrm{Fe}_{3} \mathrm{O}_{4} @ \mathrm{SiO}_{2}$ core-shell multilayer heterostructure (Fig. 4b). It is believed that the silica binding interlayer is responsible for the heterogeneous integration to synergistically improve the visiblelight-driven photocatalysis for the degradation of ibuprofen. Based on the above work, the presence of a silica binding interlayer plays an important role in the combination of multi-component to generate the synergistic effect for photocatalysis.

In the core-shell silica-based composite structures, porous silica is completely retained at different locations such as support, coating layer, and binding interlayer,

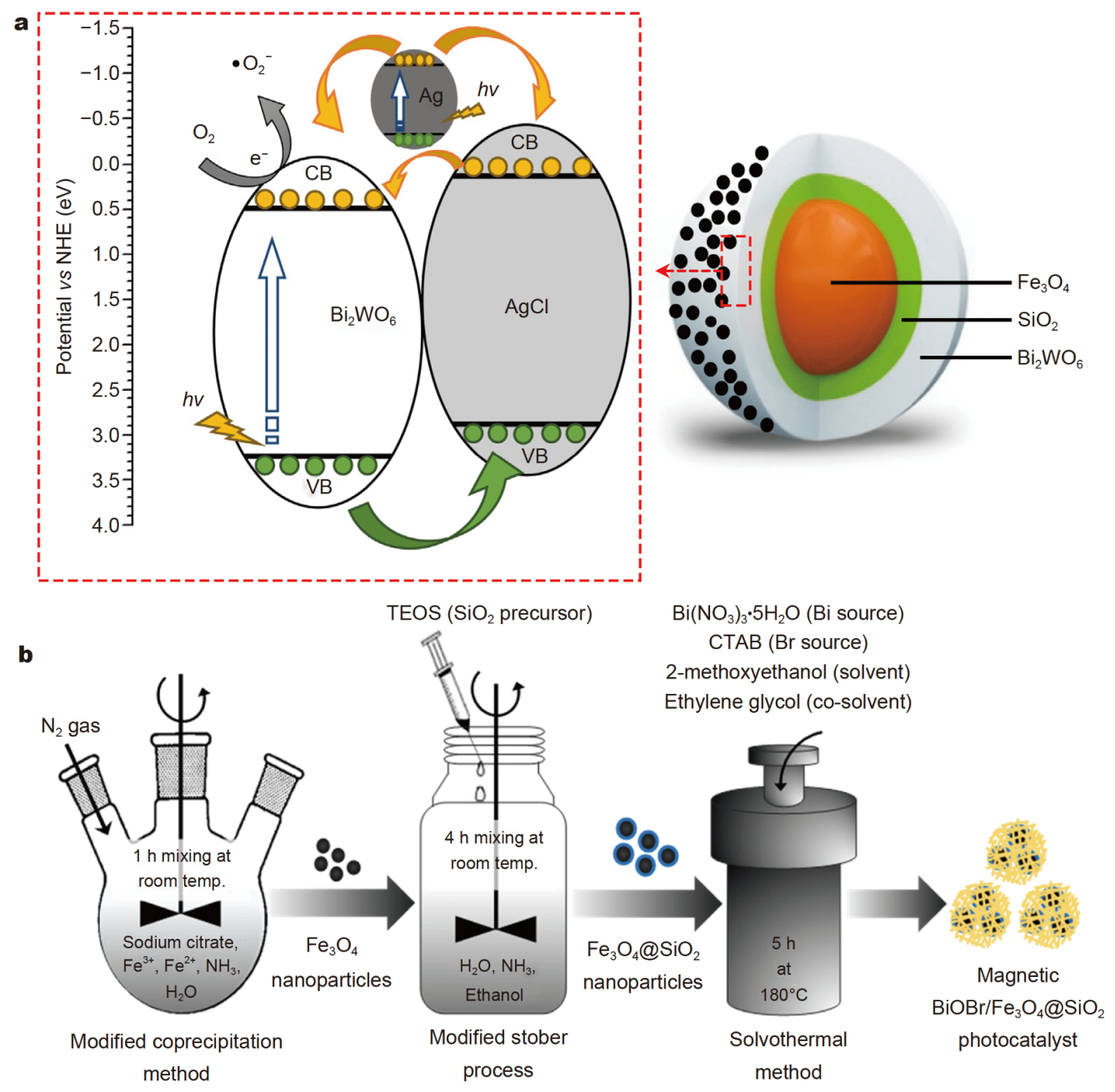

Figure 4 Proposed mechanism for the photocatalytic degradation of organic compounds in the presence of Ag/AgCl- $\mathrm{Bi}_{2} \mathrm{WO}_{6} @ \mathrm{Fe}_{3} \mathrm{O}_{4} @ S i \mathrm{~S}_{2}$. $\mathrm{Rep}-$ rinted with permission from Ref. [77]. Copyright 2016, Elsevier. (b) Schematic showing major steps in the synthesis of $\mathrm{BiOBr}_{2} \mathrm{Fe}{ }_{3} \mathrm{O}_{4} @ S i \mathrm{~S}_{2}$. Reprinted with permission from Ref. [78]. Copyright 2018, Elsevier. 
thus improving one or more behaviors for photocatalysis. Silica-supported CSNs favor the dispersibility of the photocatalyst NPs on the outer layer of silica to produce more active sites for photocatalysis. Silica coating can protect the photocatalyst core from dissolution or oxidation to improve the chemical stability and modify the surface properties to benefit the adsorption and diffusion of the reactant molecules. When introducing silica as a binding interlayer, the multiple components can be combined into a photocatalytic system to generate the synergistic effect for accelerating the photocatalytic reactions. Despite the obvious advantages brought by the silica-based CSNs, the presence of porous silica caused the stability of composite structure to be difficultly maintained in a high-temperature steam environment or alkaline media, which limited the wide applications of the composite photocatalysts. Particularly, the silica coating will partly shield the light absorption and block the active sites of the photocatalysts, which are unfavorable to the photocatalytic reaction. Therefore, it still remains great challenges to improve core-shell silica-based composite structures with enhanced photocatalytic performance.

\section{DESIGN OF YOLK-SHELL SILICA-BASED COMPOSITE PHOTOCATALYSTS}

Compared with traditional core-shell nanostructures, yolk-shell nanostructures can also successfully integrate various functional components into a single system. Besides the improvements in surface property and structural stability, YSNs can also tailor the light absorption property by the structure with hollow morphology [79]. The yolk-shell structures are composed of a movable core, nanostructured shell and cavity [80]. The core particle is encapsulated inside and behaves freely like a movable yolk in YSNs $[81,82]$. The yolk-shell nanostructures are generally assembled by templating methods by adopting the hard template (such as silica, polymer, and carbon) or surfactants as the soft template, followed by the selective removal of the template via chemical etching, calcination, or solvent extraction treatment $[83,84]$. Porous silica is considered to be an ideal sacrificial template to form the interior void space due to the low cost, durability and nontoxicity. The heterostructures with interior void have been proved to positively affect the other crucial photocatalytic behaviors of the specific surface area, charge separation and light absorption ability, besides the surface property and structural stability.

\section{Silica-supported yolk-shell structure}

In the silica-supported yolk-shell structure, silica inner core first functions as a typical support to improve the dispersibility of the materials in outer shell, and then can be selectively removed by a weak base treatment to form the hollow morphology in the heterostructure [85]. In this way, the increased light absorption by multistep reflections in inner hole and the enlarged specific surface area both contributed to the enhanced photocatalytic performance.

For instance, Gao et al. [86] reported a novel multifunctional yolk-shell $\mathrm{SiO}_{2} @ \mathrm{TiO}_{2}$ nanocomposite with the modification of carbon dots, labelled as y-STCs nanospheres (Fig. 5a). Firstly, nanosphere shaped silica core was synthesized as a template via the well-known Stöber process, and then was coated with a $\mathrm{TiO}_{2}$ shell by a sol-gel method. At last, the silica core was partially removed by $\mathrm{NH}_{4} \mathrm{~F}$ treatment to form the yolk-shell structure showing a diameter of yolk as $240 \mathrm{~nm}$, an average width of cavity as $60 \mathrm{~nm}$, and a thickness of shell as $20 \mathrm{~nm}$. The comparison with the particle size of pristine $\mathrm{SiO}_{2}$ nanospheres confirmed the partial removal by the alkaline solution. The fabricated yolk-shell $\mathrm{SiO}_{2} @ \mathrm{TiO}_{2}$ possessed larger Brunauer-Emmett-Teller (BET) surface area $\left(35 \mathrm{~m}^{2} \mathrm{~g}^{-1}\right)$ and average pore size (ca. $12 \mathrm{~nm}$ ) than those of core-shell structures, which is favorable to enhance the surfaceenhanced Raman scattering detection and catalytic effect. It could be observed that the designed YSNs exhibited higher degradation rate and cycle stability towards dinitrophenols, demonstrating the effect of partial removal of silica support in promoting the homogeneous interaction of reactants with the photocatalyst surface. Wan et al. [87] synthesized the Fe- $\mathrm{N}$ co-doped $\mathrm{SiO}_{2} @ \mathrm{TiO}_{2}$ yolk-shell hollow nanospheres by a facile sol-gel method and hydrothermal method (Fig. 5b). With the support of the hollow $\mathrm{SiO}_{2}$ core, the YSNs obtained both rich support capacity and larger specific surface area for surface adsorption, which were associated with the higher photocatalytic rate of $99.2 \%$ in degrading tannic acid than pure $\mathrm{TiO}_{2}$ nanospheres $(\sim 10 \%)$. Based on these findings, silicasupported yolk-shell photocatalysts with appropriate cavity can suppress the aggregation of photocatalyst in the outer layer and possess relatively high surface area, both of which contributed to the improvement of photocatalytic performance.

\section{Silica-coated yolk-shell structure}

For the well-defined yolk-shell structure, the porous silica can be designed as a barrier shell for the purpose of protecting the nucleus from affecting by the surrounding environment and improving the adsorption properties, analogous to a molecular-sieving configuration, besides the 


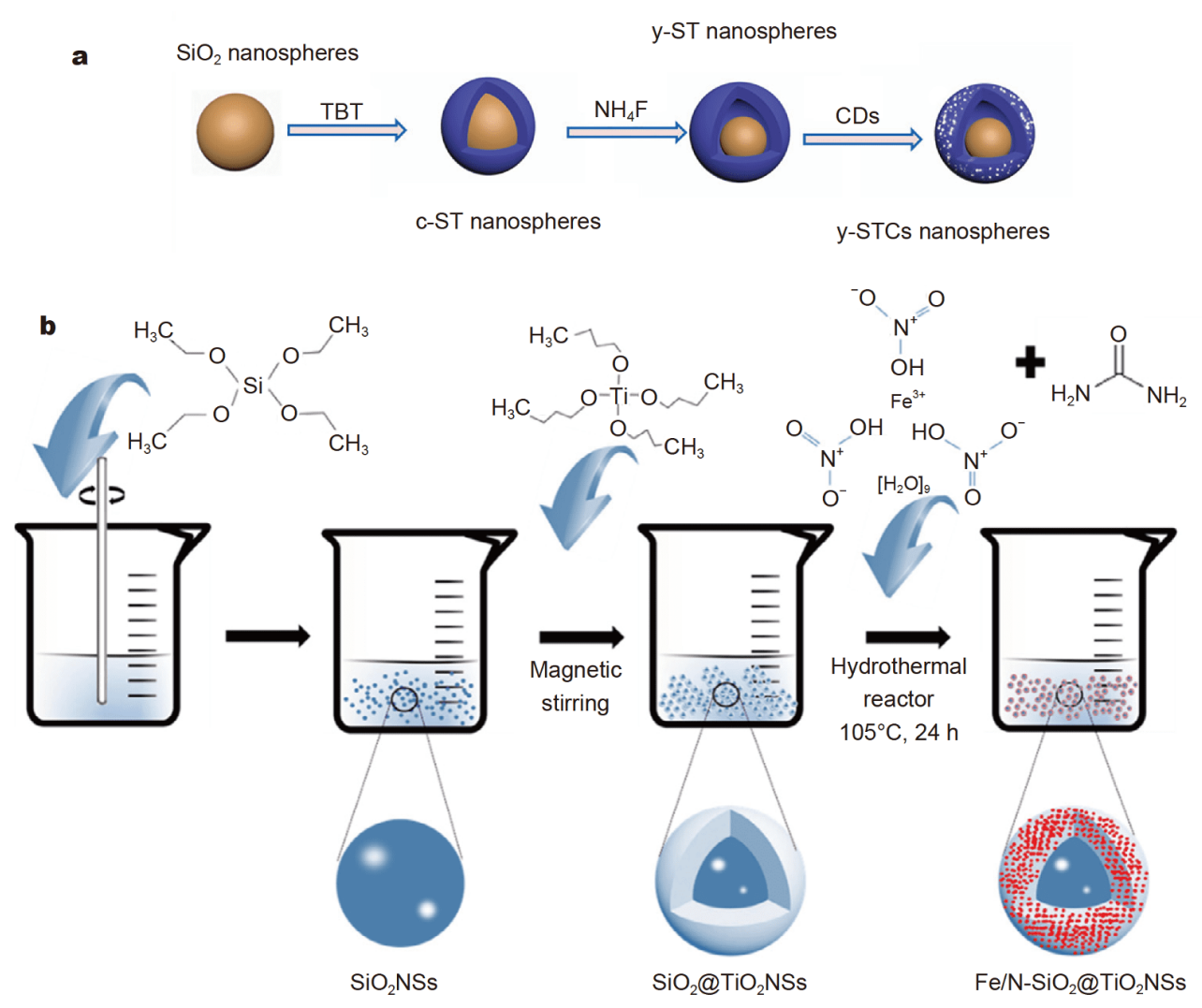

Figure 5 (a) Schematic illustration for the formation of y-STCs nanospheres. Reprinted with permission from Ref. [86]. Copyright 2018, Elsevier. (b) Schematic illustration for the formation of $\mathrm{Fe} / \mathrm{N}-\mathrm{SiO}_{2} @ \mathrm{TiO}_{2}$. Reprinted with permission from Ref. [87]. Copyright 2018, Elsevier.

merits of hollow structure for enlarging specific surface area and enhancing light absorption. In this category, the sacrificing intermediate layers are usually involved by the introduction of cationic surfactants such as cetyltrimethylammonium bromide $(\mathrm{CTAB})$, oil-in-water $(\mathrm{O} / \mathrm{W})$ microemulsion or cetyltrimethylammonium chloride [88].

For instance, $\mathrm{Mu}$ et al. [89] constructed a novel $\mathrm{Au} / \mathrm{Pd}$ heterojunction@mesoporous $\quad \mathrm{SiO}_{2} \quad$ yolk-shell nanostructure for plasmon-enhanced photocatalysis. The coating of mesoporous $\mathrm{SiO}_{2}$ was realized with the assistance of $\mathrm{CTAB}$ as the structure-directing agent. In such a yolk-shell nanostructure, the metal NPs were encapsulated in the transparent silica shell, so that the plasmonic components can efficiently harvest the visible light energy to exhibit the superior stability and catalytic activity. The organic templates like $\mathrm{O} / \mathrm{W}$ microemulsion are also used in fabricating silica-coated yolk-shell structure. The porous silica shell will be beneficial to the enhancement of the photocatalytic activity, resulting from the advantages of porous structures and the associated large surface area [90]. Fujiwara et al. [91] developed a yolk-shell nanostructured photocatalyst that encapsulated
$\mathrm{TiO}_{2} \mathrm{NPs}$ inside the spherical hollow silica shell $\left(\mathrm{TiO}_{2} @\right.$ HSS_pro) by utilizing $\mathrm{O} / \mathrm{W}$ microemulsion and amphiphilic protein molecule as templates, followed by calcination to remove the template and create a void space (Fig. 6a). The photocatalytic efficiency and molecular size selectivity were attributed to the molecular sieving property of the porous silica shell, which inhibited the access of huge reactant molecule and controlled the size selectivity toward targeted reactants (Fig. 6b). It can be concluded that the large internal surface area and tunable chemical property of porous silica will endow the silicacoated yolk-shell structure photocatalysts with the enhanced light absorption ability and molecular-sieving property.

\section{Silica-interlayered yolk-shell structure}

According to the above discussions, silica can be introduced as an interlayer to favor the incorporation of multiple components into a photocatalytic system. Upon the achievement of such well-defined heterostructures, the silica interlayer can be etched completely to form a cavity between the components, producing another type 


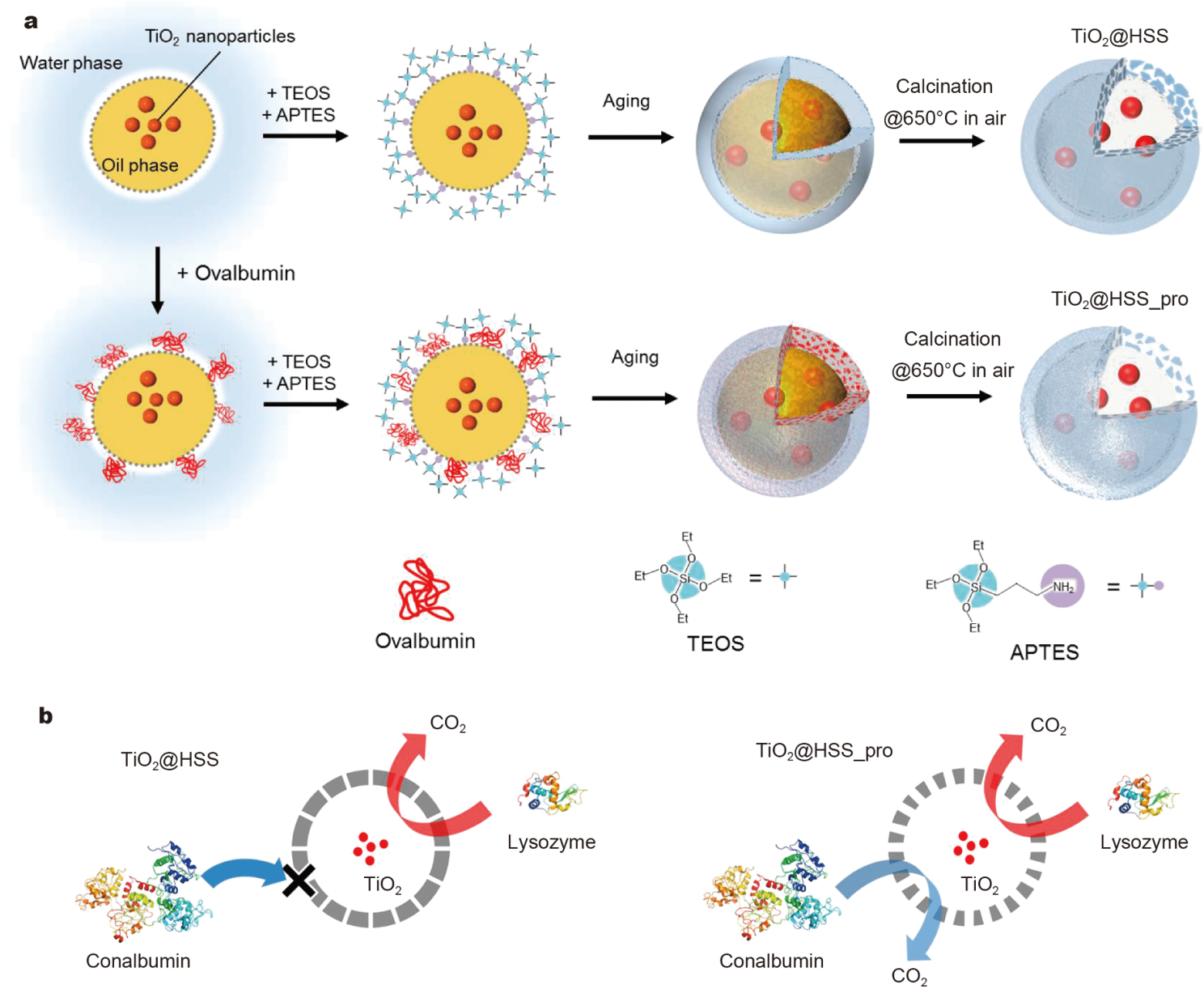

Figure 6 (a) Schematic representation of the synthetic procedure of $\mathrm{TiO}_{2} @ H S S$ and $\mathrm{TiO}_{2} @ H S S$ _pro. APTES stands for (3-aminopropyl)triethoxysilane. (b) Schematic illustrations representing the photodegradation of conalbumin and lysozyme molecules over TiO ${ }_{2}$ HSS (left) and $\mathrm{TiO}_{2} @$ HSS_pro (right). Reprinted with permission from Ref. [91]. Copyright 2017, American Chemical Society.

of yolk-shell structure (silica-interlayered YSN). The silica-etched yolk-shell composites possess highly porous structure, available inner void space, and large surface area, which are favorable to the improvement of multiple physicochemical properties, including light absorption, charge generation and separation, and structural stability $[82,92,93]$. Moreover, the metal or metal oxide can be confined in the void space to keep the morphology and dispersibility during the assembly process and photocatalytic reactions.

Lee et al. [94] reported a well-defined Au@Void@ $\mathrm{TiO}_{2}$ yolk-shell nanostructure for photocatalytic $\mathrm{H}_{2}$ production (Fig. 7a). The gold NPs were coated by a sacrificial silica layer and an outer titania shell, followed by the etching of silica interlayer using $\mathrm{NaOH}$ aqueous solution to provide sufficient space for the crystallization of the titania layer. By varying the amount of TEOS, the growth of the silica layer can be controlled to adjust the size of the void space in the YSNs. The diameter of titania shell was found to be one of the main geometrical parameters that influenced the hydrogen production rate. Shi et al. [95] reported a one-pot coating-etching process to design yolk-shell structured $\mathrm{Fe}_{3} \mathrm{O}_{4} @$ void@CdS NPs, where the inner $\mathrm{SiO}_{2}$ shell was gradually etched accompanying by the coating of an outer CdS shell by a chemical bath deposition process (Fig. 7b). The resulting yolk-shell structure displayed the void space with a radius of ca. $35 \mathrm{~nm}$ between the $\mathrm{Fe}_{3} \mathrm{O}_{4}$ core and the CdS shell, in accordance with the thickness of the original $\mathrm{SiO}_{2}$ layer, suggesting the successful etching of $\mathrm{SiO}_{2}$ during the formation of CdS shell. Compared with a series of reference catalysts, $\mathrm{Fe}_{3} \mathrm{O}_{4} @$ void@CdS was proved to possess more efficiently preadsorbing ability of $\mathrm{MB}$ (ca. $20 \%$ ) than naked $\mathrm{Fe}_{3} \mathrm{O}_{4} \mathrm{NPs}$ (ca. 8\%), in accordance with the result of better de- 
a

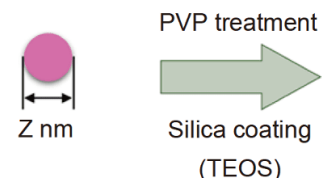

Au NPs

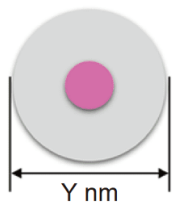

$\mathrm{Au} @ \mathrm{SiO}_{2}$

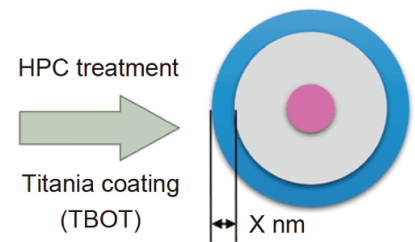

$\mathrm{Au} @ \mathrm{SiO}_{2} @ \mathrm{TiO}_{2}$

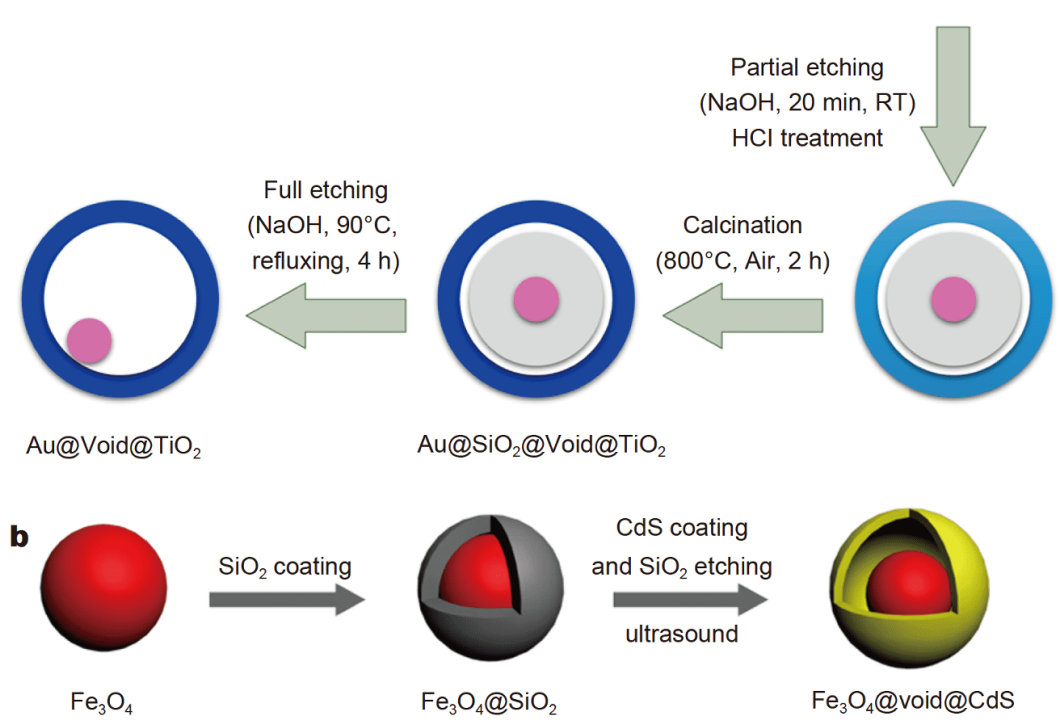

Figure 7 (a) Synthetic scheme used to make the Au@Void@ $\mathrm{TiO}_{2}$ yolk-shell nanostructures. Reprinted with permission from Ref. [94]. Copyright 2016, American Chemical Society. (b) Schematic illustration for the formation of the $\mathrm{Fe}_{3} \mathrm{O}_{4} @ v$ void@CdS NPs. Reprinted with permission from Ref. [95]. Copyright 2016, American Chemical Society.

gradation performance. This type of yolk-shell structure with tunable hollow space functioned efficiently as a nanoreactor to provide the suitable reaction place and more adsorption sites. Besides, it realized the maximum use of light irradiation derived from light reflection in the cavity. Liang et al. [96] fabricated $\mathrm{Au} @ g-\mathrm{C}_{3} \mathrm{~N}_{4} / \mathrm{SnS}$ yolk-shell Z-scheme photocatalysts by a simple template-assisted strategy. Apart from the manufacture of yolk-shell Au@g$\mathrm{C}_{3} \mathrm{~N}_{4}$ nanospheres by removing silica interlayer, the transition-metal sulfide SnS was coupled through further assembling. The unique stable hollow configuration of the designed photocatalysts significantly enhanced the reduction efficiency of carbon dioxide under visible light. The construction of such silica-interlayered yolk-shell nanostructures benefits the utilization of light sources by the multistep reflections in its inner hole and can also adjust the light absorption ability by the tunable void framework in the heterostructure.

In the yolk-shell silica-based composite structures, silica is mostly introduced as a sacrificial template, followed by a partial or complete removal treatment to create a void. Besides the existing merits as core-shell structures, the formation of hollow morphology inside YSNs is beneficial to the enlargement of specific surface area and enhancement of light absorption ability by multistep reflections in the inner hole. In particular, the photocatalysts are confined in the void space and thus the morphology as well as dispersibility can be well maintained. The advantages of light absorption, specific surface area and dispersibility all contributed to the improved photocatalytic performance. It should be noted that the construction of YSNs generally involved complex synthetic procedure and inevitably suffered from unavoidable template consumption and low yield, which hampered the large-scale production. Additionally, it is difficult to completely remove the silica or precisely adjust the partial etching of silica during the post-treatment process. As a consequence, it is highly desirable to develop facile and advanced strategies for the construction of yolk-shell silica-based composite structures.

\section{OTHER SPECIFIC SRTUCTURES OF SILICA-BASED PHOTOCATALYSTS}

In addition to the core-shell and yolk-shell spherical 
structure photocatalysts, there are some other specific silica-based nanostructures by combining silica with other materials, such as hollow nanospheres, silicasupported NPs, and silica-decorated nanosheets. These nanostructures have been rationally designed by introducing silica as the support or decoration material owing to its ordered porous structure, excellent thermal and mechanical stabilities, and large surface area [97]. It is found that the high surface area, abundant active sites, and efficient charge separation are achieved to remarkably enhance the photocatalytic efficiency [98].

\section{Hollow nanospheres}

The hollow nanospheres without entitative silica cores typically possess apparent advantages over nonhollow counterparts [99]. The high surface area, excellent light harvesting and high electron transfer efficiency, all contribute to the improved photocatalytic efficiency [53]. For example, Leshuk et al. [100] synthesized mesoporous titanium dioxide hollow spheres with high structural integrity. The silica nanosphere was used as a core template to grow a layer of $\mathrm{TiO}_{2}$ shell and then dissolved in the alkaline solutions by a hydrothermal treatment. The hollow spheres process a surface area of $\sim 300 \mathrm{~m}^{2} \mathrm{~g}^{-1}$, allowing for the superior adsorption capacity of $\mathrm{MB}$ to be photocatalytic degraded. Wang et al. [101] introduced the silica template to fabricate oxygen vacancy-rich anatase $\mathrm{TiO}_{2}$ hollow spheres, which promoted the light harvesting efficiency and accelerated the surface reaction kinetics. Within the visible light irradiation for a period of $3 \mathrm{~h}$, the $\mathrm{H}_{2}$ production of $\mathrm{TiO}_{2}$ hollow spheres was enhanced up to $1240.5 \mu \mathrm{mol}$, which was 2.5 times higher than that of samples without hollow structure $(493.1 \mu \mathrm{mol})$. Bie et al. [102] successfully fabricated the monolayer nitrogen- doped graphene (NG) on CdS hollow spheres by an in situ growth tactic (Fig. 8). The hollow sphere structure exhibited the highest $\mathrm{CO}$ and $\mathrm{CH}_{4}$ production rates of 2.59 and $0.33 \mu \mathrm{mol} \mathrm{g}^{-1} \mathrm{~h}^{-1}$, about 4 and 5 times higher than those of pure CdS, respectively. The enhancement was attributed to the strengthened light absorption by multiple light reflections, the enlarged contact area between NG and CdS, the enhanced $\mathrm{CO}_{2}$ adsorption and activation, and so on.

According to these findings, it can be concluded that the hollow spheres possess apparent advantages over nonhollow counterparts from the aspects of surface area, adsorption capacity, and light harvesting ability. Such hollow structures are expected to garner much more attention if the acceleration of photocatalytic efficiency and excess template consumption can be well-balanced.

\section{Silica-supported NPs}

As a typical support, porous silica nanospheres have been introduced for loading the photocatalyst NPs to realize better dispersion and provide more active sites for catalytic reactions. Different from the silica-supported coreshell structure, the photocatalyst NPs are scattered on the silica surface rather than existing as a coating layer. Mandal et al. [103] synthesized a $\mathrm{Fe}_{2} \mathrm{O}_{3} / \mathrm{SiO}_{2}$ composite by decorating the $\mathrm{Fe}_{2} \mathrm{O}_{3}$ NPs on the silica surface. Generally, the hematite NPs are inclined to forming the morphology of large size by their magnetic attractions. It could be observed that the agglomeration of $\mathrm{Fe}_{2} \mathrm{O}_{3}$ NPs was hindered in the presence of silica nanospheres, resulting in the increased active sites to generate more reactive oxygen species (Fig. 9a). The photocatalytic degradation reactivity of $\mathrm{MB}$ over the composite was enhanced to be 3.6 times of that over the pristine $\mathrm{Fe}_{2} \mathrm{O}_{3}$

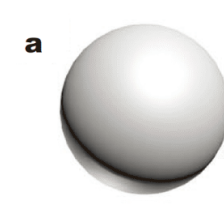

$\mathrm{SiO}_{2}$
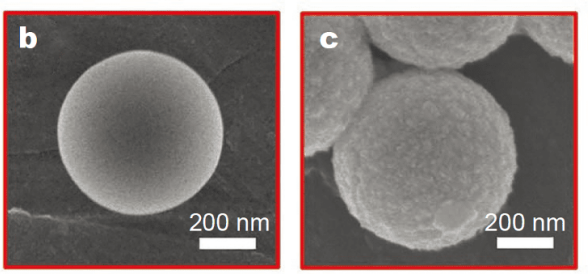
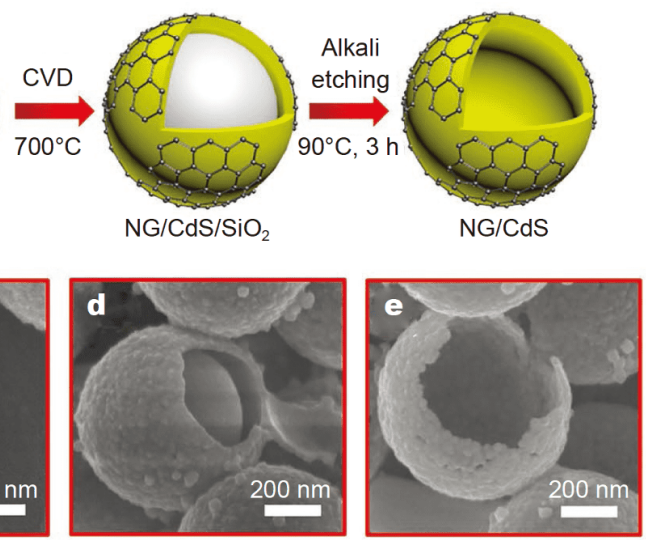

Figure 8 (a) Schematic illustration of the preparation process for NG/CdS HS. (b-e) Corresponding field-emission scanning electron microscopy (FESEM) images of the materials sequentially appearing from left to right in (a). Reprinted with permission from Ref. [102]. Copyright 2019, Wiley. 

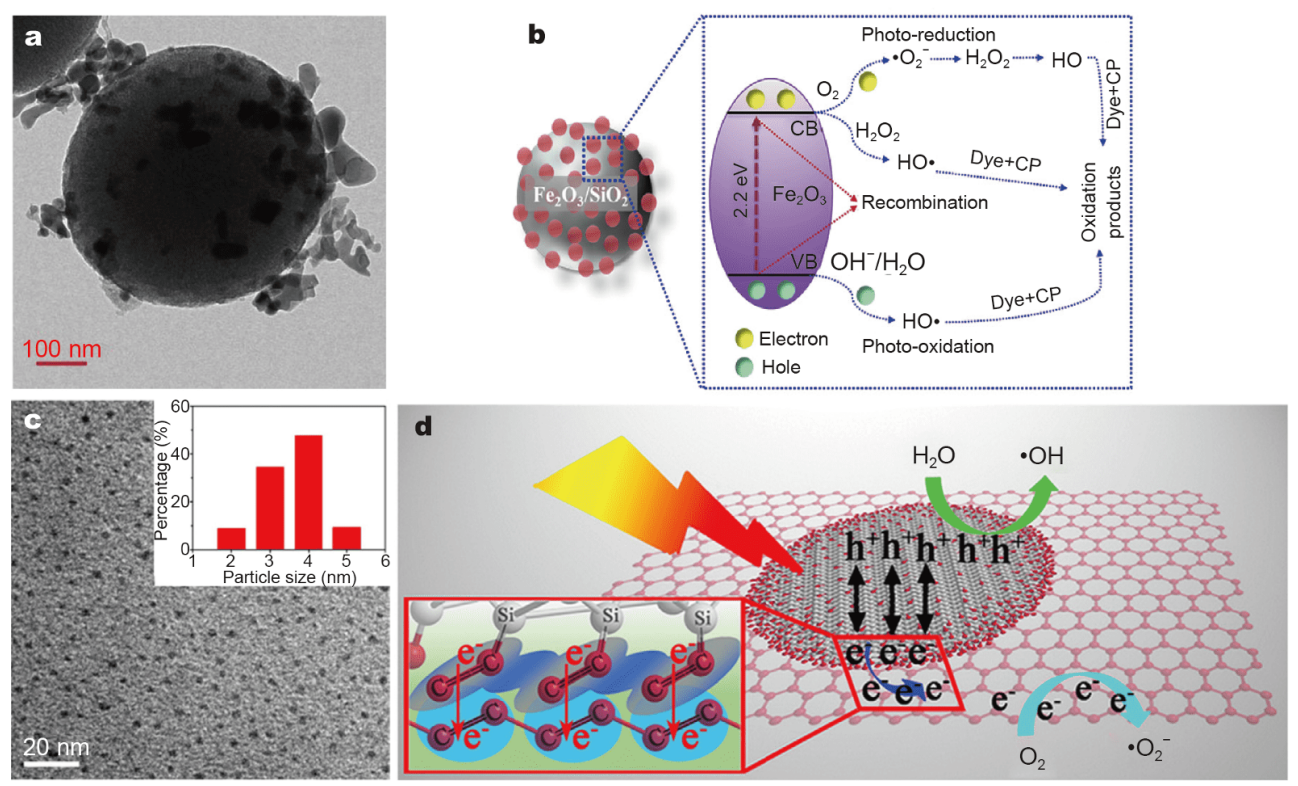

Figure 9 (a) HRTEM image of $\mathrm{Fe}_{2} \mathrm{O}_{3}-\mathrm{SiO}_{2}$ with $20 \mathrm{wt} \% \mathrm{Fe}_{2} \mathrm{O}_{3}$ loading. (b) Schematic for the photocatalytic process via $\mathrm{Fe}_{2} \mathrm{O}_{3}$ loaded on the silica nanospheres as the support. Reprinted with permission from Ref. [103]. Copyright 2019, Elsevier. (c) $\mathrm{HRTEM}$ image of the $\mathrm{SiO}_{2} \mathrm{NC/rGO}$ composite. (d) Scheme for electron transfer from $\mathrm{SiO}_{2} \mathrm{NCs}$ to rGO under light irradiation. Reprinted with permission from Ref. [105]. Copyright 2015, Elsevier.

NPs (Fig. 9b). Additionally, the high recoverability and recyclability were achieved in the photocatalytic system of the silica-supported NPs. Abdullah and co-workers [104] reported the fabrication of $\mathrm{SiO}_{2} / \mathrm{NiO} / \mathrm{Zn}(\mathrm{O}, \mathrm{S})$ nanocomposites for photocatalytic hydrogen evolution reaction in a $10 \%$ ethanol solution under light illumination of low power UV lamps. The silica provided a substrate to grow $\mathrm{Zn}(\mathrm{O}, \mathrm{S})$ and $\mathrm{NiO} \mathrm{NPs}$ and achieved the high specific surface area of $618 \mathrm{~m}^{2} \mathrm{~g}^{-1}$, which contributed to $20 \%$ of the enhancement in hydrogen evolution rate.

The silica-supported NPs suffer from the instability problem similar to the silica-supported core-shell structure due to the intrinsic drawbacks of silica in hightemperature steam environment or alkali media. Differently, the photocatalyst NPs are scattered on the silica surface rather than existing as a coating layer. Therefore, the introduction of silica support induced the formation of nano-sized photocatalysts with better dispersion and more active sites accounting for the boosting of the photocatalytic reactivity.

\section{Silica-decorated nanostructure}

Instead of acting as the support material, the silica particles can also decorate on the surfaces of other materials because of their special surface properties and controllable morphologies. For example, Yang et al. [105] reported that the growth of monodispersed silica nano- crystals $\left(\mathrm{SiO}_{2} \mathrm{NCs}\right)$ (ca. 3-4 nm) on the single-layer graphene sheet with a high deposition density (ca. $10^{16} \mathrm{~m}^{-2}$ ) using a modified Stöber process (Fig. 9c). The surface of $\mathrm{SiO}_{2}$ NCs was covered with high-density vinyl groups overlapping with each other, which facilitated the intimate contact between $\mathrm{SiO}_{2} \mathrm{NCs}$ and reduced graphene oxide ( $\mathrm{rGO}$ ), leading to the increase of $\pi$-conjugation degree of the composite relative to pure rGO (Fig. 9d). The $\mathrm{SiO}_{2} \mathrm{NCs} / \mathrm{rGO}$ composite presents better electron mobility and stronger photocurrent intensity than $\mathrm{rGO}$ or the physical mixture of $\mathrm{SiO}_{2}$ and rGO, leading to a much higher degradation rate of $0.023 \mathrm{~min}^{-1}$ than that on $\mathrm{rGO}\left(0.003 \mathrm{~min}^{-1}\right)$ towards 2,4-dichlorophenol. The improved photocurrent could be attributed to the efficient electron charging from $\mathrm{SiO}_{2} \mathrm{NCs}$ to $\mathrm{rGO}$ in the composite nanostructure. It was also reported that the $\mathrm{SiO}_{2}$-decorated $\mathrm{BiOCl}$ nanosheets displayed high photocatalytic activity and excellent stability. Compared with bare $\mathrm{BiOCl}$, the degradation rates of organic pollutants increased $38.7 \%$ for phenol, $29.0 \%$ for bisphenol $\mathrm{A}$, and $16.5 \%$ for $\mathrm{RhB}$, respectively. The presence of silica effectively improved the texture property of $\mathrm{SiO}_{2} / \mathrm{BiOCl}$ photocatalyst and resulted in a larger surface area of $15.56 \mathrm{~m}^{2} \mathrm{~g}^{-1}$ than that of $\mathrm{BiOCl}\left(4.62 \mathrm{~m}^{2} \mathrm{~g}^{-1}\right)$. Moreover, the defects and vacancy sites on the surface of $\mathrm{SiO}_{2}$ could effectively trap the photoexcited electrons through the intimate $\mathrm{SiO}_{2} / \mathrm{BiOCl}$ interfaces and thus 
promote the separation of the photoexcited charge carriers, resulting in the improved photocatalytic activity of the composite [106].

As discussed above, the silica-decorated nanostructure also possesses feasibility in modifying the surface properties of other materials with desired functional groups as the silica-coating structures. Although the silica decoration still partly decreases the light absorption and active sites, such negative effects can be greatly alleviated owing to the high dispersion of silica nanocrystals on the surface. Besides, the tunable surface property and morphology of silica facilitate the intimate contact with other materials and charge transfer between them, resulting in the improved photocatalytic activity of the composite.

\section{SUMMARY AND OUTLOOK}

In this review, we have summarized the recent advances in the silica-based nanostructures rationally designed for effective photocatalysis. The most popular nanostructures have been divided into three categories including coreshell, yolk-shell and other specific structures. Each of the structure achieved the improvement in one or more behaviors of light absorption, charge generation and separation, surface property and structural stability. The formation mechanism and the regulation of physicochemical properties have been discussed to reveal the deep understanding of the improved photocatalytic performance for typical applications such as $\mathrm{CO}_{2}$ reduction, hydrogen evolution, degradation of organic pollutants and inorganic pollutants removal.

Despite the encouraging progress having been achieved for the silica-based nanostructures in photocatalytic fields, there still exist great challenges which limit their extensive applications. Firstly, although silica possesses the above-mentioned merits in constructing composite nanostructures, its applied environment is restricted to a large extent due to its intrinsic instability in the hightemperature steam environment or alkaline solutions. For the purpose of stability improvement, it is of great importance to focus on the surface modification and functionalization of the silica-based photocatalysts. Secondly, considering the synthesis aspect, some synthesis strategies contain complicated operations and expensive materials, resulting in the time-consuming and uneconomical process. For example, the approaches of the silica-interlayered yolk-shell photocatalysts always involve multiple steps, which hampers the large-scale production. As a consequence, it is in urgent need to further develop facile and advanced methods for the assembly of silica-based nanostructures in the future. Thirdly, from the viewpoints of structure and performance relationships, silica-based nanostructures possess diverse morphologies and pore structures; however, the photocatalytic mechanisms are lacking in the deep understanding of the present studies. Hence, more research efforts should be devoted to revealing the underlying factors for the improved physicochemical properties related to photocatalysis and establishing the relationships between the designed nanostructures and photocatalytic performances, which can in turn provide guidance to the optimization of the photocatalysts with desired properties. Last, in terms of the unique structural and compositional benefits of such designed silica-based photocatalysts, the design and synthesis approaches can also be extended to construct versatile nanostructured photocatalysts using other materials (such as carbon, polymer, and metal oxides) as substitutes of silica. With continuous studies on the structural design and controlled synthesis of composites, more expansions of these functional materials can be expected for the applications of solar energy conversion and will inspire further advancements in other catalytic applications.

\section{Received 26 February 2020; accepted 5 May 2020; \\ published online 10 July 2020}

1 Fan $\mathrm{Y}, \mathrm{Hu} \mathrm{G}, \mathrm{Yu}$ S, et al. Recent advances in $\mathrm{TiO}_{2}$ nanoarrays/ graphene for water treatment and energy conversion/storage. Sci China Mater, 2018, 62: 325-340

2 Li W, Elzatahry A, Aldhayan D, et al. Core-shell structured titanium dioxide nanomaterials for solar energy utilization. Chem Soc Rev, 2018, 47: 8203-8237

3 Wang J, Xu M, Zhao J, et al. Anchoring ultrafine Pt electrocatalysts on $\mathrm{TiO}_{2}-\mathrm{C}$ via photochemical strategy to enhance the stability and efficiency for oxygen reduction reaction. Appl Catal B-Environ, 2018, 237: 228-236

4 Lv K, Yu J, Deng K, et al. Synergistic effects of hollow structure and surface fluorination on the photocatalytic activity of titania. J Hazard Mater, 2010, 173: 539-543

5 Zhang K, Ran J, Zhu B, et al. Nanoconfined nickel@carbon coreshell cocatalyst promoting highly efficient visible-light photocatalytic $\mathrm{H}_{2}$ production. Small, 2018, 14: 1801705

$6 \mathrm{Li} \mathrm{X}, \mathrm{Yu} \mathrm{J}$, Jaroniec M, et al. Cocatalysts for selective photoreduction of $\mathrm{CO}_{2}$ into solar fuels. Chem Rev, 2019, 119: 39624179

7 Xia Y, Li Q, Lv K, et al. Heterojunction construction between $\mathrm{TiO}_{2}$ hollowsphere and $\mathrm{ZnIn}_{2} \mathrm{~S}_{4}$ flower for photocatalysis application. Appl Surf Sci, 2017, 398: 81-88

8 Li Q, Xia Y, Yang C, et al. Building a direct Z-scheme heterojunction photocatalyst by $\mathrm{ZnIn}_{2} \mathrm{~S}_{4}$ nanosheets and $\mathrm{TiO}_{2}$ hollowspheres for highly-efficient artificial photosynthesis. Chem Eng J, 2018, 349: 287-296

9 Qi K, Cheng B, Yu J, et al. A review on $\mathrm{TiO}_{2}$-based Z-scheme photocatalysts. Chin J Catal, 2017, 38: 1936-1955

10 Wang S, Xu M, Peng T, et al. Porous hypercrosslinked polymer$\mathrm{TiO}_{2}$-graphene composite photocatalysts for visible-light-driven 
$\mathrm{CO}_{2}$ conversion. Nat Commun, 2019, 10: 676

11 Tang $\mathrm{Y}$, Zhou $\mathrm{P}$, Wang $\mathrm{K}$, et al. BiOCl/ultrathin polyaniline core/ shell nanosheets with a sensitization mechanism for efficient visible-light-driven photocatalysis. Sci China Mater, 2018, 62: 95102

$12 \mathrm{Fu}$ J, Yu J, Jiang C, et al. g- $\mathrm{C}_{3} \mathrm{~N}_{4}$-based heterostructured photocatalysts. Adv Energy Mater, 2018, 8: 1701503

13 Zhang X, Wei W, Zhang S, et al. Advanced 3D nanohybrid foam based on graphene oxide: facile fabrication strategy, interfacial synergetic mechanism, and excellent photocatalytic performance. Sci China Mater, 2019, 62: 1888-1897

14 Chen S, Yu J, Zhang J. Enhanced photocatalytic $\mathrm{CO}_{2}$ reduction activity of MOF-derived $\mathrm{ZnO} / \mathrm{NiO}$ porous hollow spheres. $\mathrm{J} \mathrm{CO}_{2}$ Util, 2018, 24: 548-554

$15 \mathrm{Xu} \mathrm{M}, \mathrm{Hu} \mathrm{X}$, Wang $\mathrm{S}$, et al. Photothermal effect promoting $\mathrm{CO}_{2}$ conversion over composite photocatalyst with high graphene content. J Catal, 2019, 377: 652-661

16 Ma Y, Wang Z, Xu X, et al. Review on porous nanomaterials for adsorption and photocatalytic conversion of $\mathrm{CO}_{2}$. Chin J Catal, 2017, 38: 1956-1969

17 Han C, Li J, Ma Z, et al. Black phosphorus quantum dot/g- $\mathrm{C}_{3} \mathrm{~N}_{4}$ composites for enhanced $\mathrm{CO}_{2}$ photoreduction to CO. Sci China Mater, 2018, 61: 1159-1166

18 Xia Y, Cheng B, Fan J, et al. Near-infrared absorbing 2D/3D $\mathrm{ZnIn}_{2} \mathrm{~S}_{4} / \mathrm{N}$-doped graphene photocatalyst for highly efficient $\mathrm{CO}_{2}$ capture and photocatalytic reduction. Sci China Mater, 2020, 63: 552-565

19 Jin $\mathrm{Y}$, Zhang $\mathrm{H}$, Song $\mathrm{C}$, et al. Hollow $\mathrm{Zn}_{x} \mathrm{Cd}_{1-x} \mathrm{~S}$ nanospheres with enhanced photocatalytic activity under visible light. Sci Rep, 2016, 6: 29997

20 Ren D, Shen R, Jiang Z, et al. Highly efficient visible-light photocatalytic $\mathrm{H}_{2}$ evolution over $2 \mathrm{D}-2 \mathrm{D} \mathrm{CdS} / \mathrm{Cu}_{7} \mathrm{~S}_{4}$ layered heterojunctions. Chin J Catal, 2020, 41: 31-40

21 Wang $\mathrm{H}, \mathrm{Hu} \mathrm{X}, \mathrm{Ma} \mathrm{Y}$, et al. Nitrate-group-grafting-induced assembly of rutile $\mathrm{TiO}_{2}$ nanobundles for enhanced photocatalytic hydrogen evolution. Chin J Catal, 2020, 41: 95-102

22 Tang Y, Zhou P, Chao Y, et al. Face-to-face engineering of ultrathin Pd nanosheets on amorphous carbon nitride for efficient photocatalytic hydrogen production. Sci China Mater, 2019, 62: 351-358

23 Zhang L, Cui Y, Yang F, et al. Electroless-hydrothermal construction of nickel bridged nickel sulfide@mesoporous carbon nitride hybrids for highly efficient noble metal-free photocatalytic $\mathrm{H}_{2}$ production. J Mater Sci Tech, 2020, 45: 176-186

24 Chen J, Liu W, Li Z, et al. Thermally-assisted photodegradation of lignin by $\mathrm{TiO}_{2} / \mathrm{H}_{2} \mathrm{O}_{2}$ under visible/near-infrared light irradiation. Sci China Mater, 2018, 61: 382-390

$25 \mathrm{Yu} \mathrm{Y,} \mathrm{Yan} \mathrm{L,} \mathrm{Cheng} \mathrm{J,} \mathrm{et} \mathrm{al.} \mathrm{Mechanistic} \mathrm{insights} \mathrm{into} \mathrm{TiO}_{2}$ thickness in $\mathrm{Fe}_{3} \mathrm{O}_{4} @ \mathrm{TiO}_{2}-\mathrm{GO}$ composites for enrofloxacin photodegradation. Chem Eng J, 2017, 325: 647-654

$26 \mathrm{Lu} \mathrm{Z}, \mathrm{Yu} \mathrm{Z}$, Dong J, et al. Facile microwave synthesis of a Zscheme imprinted $\mathrm{ZnFe}_{2} \mathrm{O}_{4} / \mathrm{Ag} / \mathrm{PEDOT}$ with the specific recognition ability towards improving photocatalytic activity and selectivity for tetracycline. Chem Eng J, 2018, 337: 228-241

27 Wang $\mathrm{P}$, Qi C, Hao L, et al. Sepiolite $/ \mathrm{Cu}_{2} \mathrm{O} / \mathrm{Cu}$ photocatalyst: preparation and high performance for degradation of organic dye. J Mater Sci Tech, 2019, 35: 285-291

28 Liu J, Zhao Z, Xu C, et al. Structure, synthesis, and catalytic properties of nanosize cerium-zirconium-based solid solutions in environmental catalysis. Chin J Catal, 2019, 40: 1438-1487
29 Liu J, Wang L, Song W, et al. $\mathrm{BiMO}_{x}$ semiconductors as catalysts for photocatalytic decomposition of $\mathrm{N}_{2} \mathrm{O}$ : a combination of experimental and DFT+U study. ACS Sustain Chem Eng, 2019, 7: 2811-2820

30 Parrino F, Loddo V, Augugliaro V, et al. Heterogeneous photocatalysis: guidelines on experimental setup, catalyst characterization, interpretation, and assessment of reactivity. Catal Rev, 2019, 61: 163-213

31 Wang M, Peng Z, Qian J, et al. Highly efficient solar-driven photocatalytic degradation on environmental pollutants over a novel C fibers@MoSe 2 nanoplates core-shell composite. J Hazard Mater, 2018, 347: 403-411

32 Lu Z, Zhou G, Song M, et al. Development of magnetic imprinted PEDOT/CdS heterojunction photocatalytic nanoreactors: 3dimensional specific recognition for selectively photocatalyzing danofloxacin mesylate. Appl Catal B-Environ, 2020, 268: 118433

33 He F, Meng A, Cheng B, et al. Enhanced photocatalytic $\mathrm{H}_{2}$ production activity of $\mathrm{WO}_{3} / \mathrm{TiO}_{2}$ step-scheme heterojunction by graphene modification. Chin J Catal, 2020, 41: 9-20

34 Li J, Wu N. Semiconductor-based photocatalysts and photoelectrochemical cells for solar fuel generation: a review. Catal Sci Technol, 2015, 5: 1360-1384

35 He D, Zhang C, Zeng G, et al. A multifunctional platform by controlling of carbon nitride in the core-shell structure: from design to construction, and catalysis applications. Appl Catal BEnviron, 2019, 258: 117957

36 Liu J, Cheng $\mathrm{H}$, Bao J, et al. Aluminum hydroxide-mediated synthesis of mesoporous metal oxides by a mechanochemical nanocasting strategy. J Mater Chem A, 2019, 7: 22977-22985

37 Deng Y, Yue Q, Sun J, et al. Recent advance in interfacial assembly growth of mesoporous silica on magnetite particles. Angew Chem Int Ed, 2020, 59: 15804-15817

38 Liang J, Liang Z, Zou R, et al. Heterogeneous catalysis in zeolites, mesoporous silica, and metal-organic frameworks. Adv Mater, 2017, 29: 1701139

39 Fujiwara K, Kuwahara Y, Sumida Y, et al. Fabrication of photocatalytic paper using $\mathrm{TiO}_{2}$ nanoparticles confined in hollow silica capsules. Langmuir, 2017, 33: 288-295

40 Wang D, Han D, Shi Z, et al. Optimized design of threedimensional multi-shell $\mathrm{Fe}_{3} \mathrm{O}_{4} / \mathrm{SiO}_{2} / \mathrm{ZnO} / \mathrm{ZnSe}$ microspheres with type II heterostructure for photocatalytic applications. Appl Catal B-Environ, 2018, 227: 61-69

41 Tang X, Feng Q, Liu K, et al. A simple and innovative route to remarkably enhance the photocatalytic performance of $\mathrm{TiO}_{2}$ : using micro-meso porous silica nanofibers as carrier to support highly-dispersed $\mathrm{TiO}_{2}$ nanoparticles. Microporous Mesoporous Mater, 2018, 258: 251-261

42 Wang $\mathrm{H}$, Liu $\mathrm{H}$, Wang $\mathrm{S}$, et al. Influence of tunable pore size on photocatalytic and photoelectrochemical performances of hierarchical porous $\mathrm{TiO}_{2} / \mathrm{C}$ nanocomposites synthesized via dualtemplating. Appl Catal B-Environ, 2018, 224: 341-349

43 Gawande MB, Goswami A, Asefa T, et al. Core-shell nanoparticles: synthesis and applications in catalysis and electrocatalysis. Chem Soc Rev, 2015, 44: 7540-7590

44 Mohanty S, Babu P, Parida K, et al. Surface-plasmon-resonanceinduced photocatalysis by core-shell $\mathrm{SiO}_{2} @ \mathrm{Ag} \mathrm{NCs} @ \mathrm{Ag}_{3} \mathrm{PO}_{4}$ toward water-splitting and phenol oxidation reactions. Inorg Chem, 2019, 58: 9643-9654

45 Singh R, Bapat R, Qin L, et al. Atomic layer deposited (ALD) $\mathrm{TiO}_{2}$ on fibrous nano-silica (KCC-1) for photocatalysis: nanoparticle 
formation and size quantization effect. ACS Catal, 2016, 6: 27702784

46 Yin $\mathrm{Q}, \mathrm{Wu} \mathrm{W}$, Qiao R, et al. Glucose-assisted transformation of Ni-doped-ZnO@carbon to a Ni-doped-ZnO@void@SiO 2 coreshell nanocomposite photocatalyst. RSC Adv, 2016, 6: 3865338661

47 Sun $\mathrm{L}, \mathrm{Wu} \mathrm{W}$, Yang $\mathrm{S}$, et al. Template and silica interlayer tailorable synthesis of spindle-like multilayer $\alpha-\mathrm{Fe}_{2} \mathrm{O}_{3} / \mathrm{Ag} / \mathrm{SnO}_{2}$ ternary hybrid architectures and their enhanced photocatalytic activity. ACS Appl Mater Interfaces, 2014, 6: 1113-1124

48 Yang J, Wang J, Li X, et al. Synthesis of urchin-like $\mathrm{Fe}_{3} \mathrm{O}_{4} @$ $\mathrm{SiO}_{2} @ \mathrm{ZnO} / \mathrm{CdS}$ core-shell microspheres for the repeated photocatalytic degradation of rhodamine B under visible light. Catal Sci Technol, 2016, 6: 4525-4534

49 Sun L, Han X, Jiang Z, et al. Fabrication of cubic $\mathrm{Zn}_{2} \mathrm{SnO}_{4} / \mathrm{SnO}_{2}$ complex hollow structures and their sunlight-driven photocatalytic activity. Nanoscale, 2016, 8: 12858-12862

50 Zhao Z, Wang X, Shu Z, et al. Facile preparation of hollownanosphere based mesoporous $\mathrm{g}-\mathrm{C}_{3} \mathrm{~N}_{4}$ for highly enhanced visible-light-driven photocatalytic hydrogen evolution. Appl Surf Sci, 2018, 455: 591-598

51 Li Z, Li M, Bian Z, et al. Design of highly stable and selective core/ yolk-shell nanocatalysts-a review. Appl Catal B-Environ, 2016, 188: 324-341

52 Li A, Zhu W, Li C, et al. Rational design of yolk-shell nanostructures for photocatalysis. Chem Soc Rev, 2019, 48: 1874-1907

53 Xiao M, Wang Z, Lyu M, et al. Hollow nanostructures for photocatalysis: advantages and challenges. Adv Mater, 2019, 31: 1801369

54 Feng H, Tang L, Zeng G, et al. Core-shell nanomaterials: applications in energy storage and conversion. Adv Colloid Interface Sci, 2019, 267: 26-46

$55 \mathrm{Li} \mathrm{W}$, Zhao D. Extension of the Stöber method to construct mesoporous $\mathrm{SiO}_{2}$ and $\mathrm{TiO}_{2}$ shells for uniform multifunctional core-shell structures. Adv Mater, 2013, 25: 142-149

56 Stöber W, Fink A, Bohn E. Controlled growth of monodisperse silica spheres in the micron size range. J Colloid Interface Sci, 1968, 26: 62-69

57 Gopalan Sibi M, Verma D, Kim J. Magnetic core-shell nanocatalysts: promising versatile catalysts for organic and photocatalytic reactions. Catal Rev, 2020, 62: 163-311

$58 \mathrm{Wu}$ L, Zhou Y, Nie W, et al. Synthesis of highly monodispersed teardrop-shaped core-shell $\mathrm{SiO}_{2} / \mathrm{TiO}_{2}$ nanoparticles and their photocatalytic activities. Appl Surf Sci, 2015, 351: 320-326

59 Guan Z, Xu Z, Li Q, et al. AgIn $\mathrm{S}_{8}$ nanoparticles anchored on 2D layered $\mathrm{ZnIn}_{2} \mathrm{~S}_{4}$ to form $0 \mathrm{D} / 2 \mathrm{D}$ heterojunction for enhanced visible-light photocatalytic hydrogen evolution. Appl Catal BEnviron, 2018, 227: 512-518

60 Bellardita M, Addamo M, Di Paola A, et al. Photocatalytic activity of $\mathrm{TiO}_{2} / \mathrm{SiO}_{2}$ systems. J Hazard Mater, 2010, 174: 707-713

61 Ullah S, Ferreira-Neto EP, Pasa AA, et al. Enhanced photocatalytic properties of core@shell $\mathrm{SiO}_{2} @ \mathrm{TiO}_{2}$ nanoparticles. Appl Catal B-Environ, 2015, 179: 333-343

62 Liu J, Feng J, Gui J, et al. Metal@semiconductor core-shell nanocrystals with atomically organized interfaces for efficient hot electron-mediated photocatalysis. Nano Energy, 2018, 48: 44-52

63 Lee R, Kumaresan Y, Yoon SY, et al. Design of gold nanoparticles-decorated $\mathrm{SiO}_{2} @ \mathrm{TiO}_{2}$ core/shell nanostructures for visible light-activated photocatalysis. RSC Adv, 2017, 7: 74697475
64 Ye M, Zhou H, Zhang T, et al. Preparation of $\mathrm{SiO}_{2} @ \mathrm{Au} @ \mathrm{TiO}_{2}$ core-shell nanostructures and their photocatalytic activities under visible light irradiation. Chem Eng J, 2013, 226: 209-216

$65 \mathrm{Ma}$ J, Guo X, Ge H, et al. Seed-mediated photodeposition route to Ag-decorated $\mathrm{SiO}_{2} @ \mathrm{TiO}_{2}$ microspheres with ideal core-shell structure and enhanced photocatalytic activity. Appl Surf Sci, 2018, 434: 1007-1014

66 Zelekew OA, Kuo DH, Yassin JM, et al. Synthesis of efficient silica supported $\mathrm{TiO}_{2} / \mathrm{Ag}_{2} \mathrm{O}$ heterostructured catalyst with enhanced photocatalytic performance. Appl Surf Sci, 2017, 410: $454-463$

67 Liu X, Feng J, Wu B, et al. Monodisperse spherical sandwiched core-shell structured $\mathrm{SiO}_{2}-\mathrm{Au}-\mathrm{Ta}_{2} \mathrm{O}_{5}$ and $\mathrm{SiO}_{2}-\mathrm{Au}-\mathrm{Ta}_{3} \mathrm{~N}_{5}$ composites as visible-light plasmonic photocatalysts. Int J Hydrog Energy, 2018, 43: 20546-20562

68 Lin B, Xue C, Yan X, et al. Facile fabrication of novel $\mathrm{SiO}_{2} / \mathrm{g}_{-} \mathrm{C}_{3} \mathrm{~N}_{4}$ core-shell nanosphere photocatalysts with enhanced visible light activity. Appl Surf Sci, 2015, 357: 346-355

69 Liu X, Zhao L, Domen K, et al. Photocatalytic hydrogen production using visible-light-responsive $\mathrm{Ta}_{3} \mathrm{~N}_{5}$ photocatalyst supported on monodisperse spherical $\mathrm{SiO}_{2}$ particulates. Mater Res Bull, 2014, 49: 58-65

$70 \mathrm{Lu} \mathrm{Z}$, Zhou G, Song M, et al. Magnetic functional heterojunction reactors with $3 \mathrm{D}$ specific recognition for selective photocatalysis and synergistic photodegradation in binary antibiotic solutions. J Mater Chem A, 2019, 7: 13986-14000

71 Gong Y, Wang DP, Wu R, et al. New insights into the photocatalytic activity of 3-D core-shell P25@silica nanocomposites: impact of mesoporous coating. Dalton Trans, 2017, 46: 49945002

72 Hu J, Wang H, Dong F, et al. A new strategy for utilization of NIR from solar energy-promotion effect generated from photothermal effect of $\mathrm{Fe}_{3} \mathrm{O}_{4} @ \mathrm{SiO}_{2}$ for photocatalytic oxidation of NO. Appl Catal B-Environ, 2017, 204: 584-592

73 Yan $\mathrm{X}$, Zhu X, Li R, et al. Au/BiOCl heterojunction within mesoporous silica shell as stable plasmonic photocatalyst for efficient organic pollutants decomposition under visible light. J Hazard Mater, 2016, 303: 1-9

74 Nadrah P, Gaberšček M, Sever Škapin A. Selective degradation of model pollutants in the presence of core@shell $\mathrm{TiO}_{2} @ \mathrm{SiO}_{2}$ photocatalyst. Appl Surf Sci, 2017, 405: 389-394

75 Giesriegl A, Blaschke J, Naghdi S, et al. Rate-limiting steps of dye degradation over titania-silica core-shell photocatalysts. Catalysts, 2019, 9: 583

76 Ye M, Zhang Q, Hu Y, et al. Magnetically recoverable core-shell nanocomposites with enhanced photocatalytic activity. Chem Eur J, 2010, 16: 6243-6250

77 Meng $\mathrm{X}$, Zhang Z. Synthesis and characterization of plasmonic and magnetically separable Ag/ $\mathrm{AgCl}-\mathrm{Bi}_{2} \mathrm{WO}_{6} @ \mathrm{Fe}_{3} \mathrm{O}_{4} @ \mathrm{SiO}_{2}$ coreshell composites for visible light-induced water detoxification. J Colloid Interface Sci, 2017, 485: 296-307

78 Khan M, Fung CSL, Kumar A, et al. Magnetically separable $\mathrm{BiOBr} / \mathrm{Fe}_{3} \mathrm{O}_{4} @ \mathrm{SiO}_{2}$ for visible-light-driven photocatalytic degradation of ibuprofen: mechanistic investigation and prototype development. J Hazard Mater, 2019, 365: 733-743

79 Lin LS, Song J, Yang HH, et al. Yolk-shell nanostructures: design, synthesis, and biomedical applications. Adv Mater, 2018, 30: 1704639

80 Guo X, González KS, Lynn DM. Templated synthesis of polymerbased yolk/shell particles with tunable morphologies. Chem 
Mater, 2019, 31: 7443-7452

81 Yue Q, Li J, Zhang Y, et al. Plasmolysis-inspired nanoengineering of functional yolk-shell microspheres with magnetic core and mesoporous silica shell. J Am Chem Soc, 2017, 139: 15486-15493

82 Purbia R, Paria S. Yolk/shell nanoparticles: classifications, synthesis, properties, and applications. Nanoscale, 2015, 7: 19789-19873

83 Chen Y, Chen HR, Shi JL. Construction of homogenous/heterogeneous hollow mesoporous silica nanostructures by silica-etching chemistry: principles, synthesis, and applications. Acc Chem Res, 2013, 47: 125-137

84 Guiet A, Göbel C, Klingan K, et al. Hydrophobic nanoreactor soft-templating: a supramolecular approach to yolk@shell materials. Adv Funct Mater, 2015, 25: 6228-6240

85 Yoo JB, Yoo HJ, Lim BW, et al. Controlled synthesis of monodisperse $\mathrm{SiO}_{2}-\mathrm{TiO}_{2}$ microspheres with a yolk-shell structure as effective photocatalysts. ChemSusChem, 2012, 5: 2334-2340

86 Gao X, Wang X, Yang Z, et al. A novel bi-functional $\mathrm{SiO}_{2} @ \mathrm{TiO}_{2} /$ CDs nanocomposite with yolk-shell structure as both efficient SERS substrate and photocatalyst. Appl Surf Sci, 2019, 475: 135142

87 Wan $\mathrm{H}$, Yao W, Zhu W, et al. Fe-N co-doped $\mathrm{SiO}_{2} @ \mathrm{TiO}_{2}$ yolkshell hollow nanospheres with enhanced visible light photocatalytic degradation. Appl Surf Sci, 2018, 444: 355-363

$88 \mathrm{Wu}$ XJ, Xu D. Soft template synthesis of yolk/silica shell particles. Adv Mater, 2010, 22: 1516-1520

$89 \mathrm{Mu}$ Y, Zhang H, Zheng W, et al. Highly stable Au/Pd@mesoporous $\mathrm{SiO}_{2}$ yolk-shell hetero-nanostructures for plasmonenhanced visible light driven catalytic reactions. New J Chem, 2017, 41: 786-792

90 Hanske C, Sanz-Ortiz MN, Liz-Marzán LM. Silica-coated plasmonic metal nanoparticles in action. Adv Mater, 2018, 30: 1707003

91 Fujiwara K, Kuwahara Y, Sumida Y, et al. Controlling photocatalytic activity and size selectivity of $\mathrm{TiO}_{2}$ encapsulated in hollow silica spheres by tuning silica shell structures using sacrificial biomolecules. Langmuir, 2017, 33: 6314-6321

92 Chen J, Wang D, Qi J, et al. Monodisperse hollow spheres with sandwich heterostructured shells as high-performance catalysts via an extended $\mathrm{SiO}_{2}$ template method. Small, 2015, 11: 420-425

93 Li Y, Shi J. Hollow-structured mesoporous materials: Chemical synthesis, functionalization and applications. Adv Mater, 2014, 26: 3176-3205

94 Lee YJ, Joo JB, Yin Y, et al. Evaluation of the effective photoexcitation distances in the photocatalytic production of $\mathrm{H}_{2}$ from water using Au@Void@TiO 2 yolk-shell nanostructures. ACS Energy Lett, 2016, 1: 52-56

95 Shi W, Du D, Shen B, et al. Synthesis of yolk-shell structured $\mathrm{Fe}_{3} \mathrm{O}_{4} @ v o i d @ C d S$ nanoparticles: a general and effective structure design for photo-fenton reaction. ACS Appl Mater Interfaces, 2016, 8: 20831-20838

96 Liang M, Borjigin T, Zhang Y, et al. Z-scheme Au@Void@g-
$\mathrm{C}_{3} \mathrm{~N}_{4} / \mathrm{SnS}$ yolk-shell heterostructures for superior photocatalytic $\mathrm{CO}_{2}$ reduction under visible light. ACS Appl Mater Interfaces, 2018, 10: 34123-34131

97 Yamashita H, Mori K, Kuwahara Y, et al. Single-site and nanoconfined photocatalysts designed in porous materials for environmental uses and solar fuels. Chem Soc Rev, 2018, 47: 80728096

98 Zheng Y, Cai J, Lv K, et al. Hydrogen peroxide assisted rapid synthesis of $\mathrm{TiO}_{2}$ hollow microspheres with enhanced photocatalytic activity. Appl Catal B-Environ, 2014, 147: 789-795

99 Zhang P, Lou XWD. Design of heterostructured hollow photocatalysts for solar-to-chemical energy conversion. Adv Mater, 2019, 31: 1900281

100 Leshuk T, Linley S, Baxter G, et al. Mesoporous hollow sphere titanium dioxide photocatalysts through hydrothermal silica etching. ACS Appl Mater Interfaces, 2012, 4: 6062-6070

101 Wang G, Yue F, Zhang L, et al. Oxygen vacancy-rich anatase $\mathrm{TiO}_{2}$ hollow spheres via liquid nitrogen quenching process for enhanced photocatalytic hydrogen evolution. ChemCatChem, 2018, 11: 1057-1063

102 Bie C, Zhu B, Xu F, et al. In situ grown monolayer $\mathrm{N}$-doped graphene on CdS hollow spheres with seamless contact for photocatalytic $\mathrm{CO}_{2}$ reduction. Adv Mater, 2019, 31: 1902868

103 Mandal S, Adhikari S, Pu S, et al. Interactive $\mathrm{Fe}_{2} \mathrm{O}_{3} /$ porous $\mathrm{SiO}_{2}$ nanospheres for photocatalytic degradation of organic pollutants: kinetic and mechanistic approach. Chemosphere, 2019, 234: 596607

104 Abdullah H, Gultom NS, Kuo DH. Depletion-zone size control of p-type $\mathrm{NiO} / \mathrm{n}$-type $\mathrm{Zn}(\mathrm{O}, \mathrm{S})$ nanodiodes on high-surface-area $\mathrm{SiO}_{2}$ nanoparticles as a strategy to significantly enhance hydrogen evolution rate. Appl Catal B-Environ, 2020, 261: 118223

105 Yang L, Wang L, Xing M, et al. Silica nanocrystal/graphene composite with improved photoelectric and photocatalytic performance. Appl Catal B-Environ, 2016, 180: 106-112

$106 \mathrm{Yu} \mathrm{C}, \mathrm{He} \mathrm{H}$, Liu X, et al. Novel $\mathrm{SiO}_{2}$ nanoparticle-decorated $\mathrm{BiOCl}$ nanosheets exhibiting high photocatalytic performances for the removal of organic pollutants. Chin J Catal, 2019, 40: $1212-1221$

Acknowledgements This work was supported by the National Natural Science Foundation of China (21771070 and 21571071) and the Fundamental Research Funds for the Central Universities (2018KFYYXJJ120 and 2019KFYRCPY104).

Author contributions Wang $\mathrm{H}$ and Tang Q wrote the manuscript, prepared the figures, and analyzed the references; Chen $\mathrm{Z}$ participated in the data analysis; Li T provided the helpful discussions; Wang J conceived the idea and revised the manuscript. All authors participated in the general discussion.

Conflict of interest The authors declare that they have no conflict of interest. 


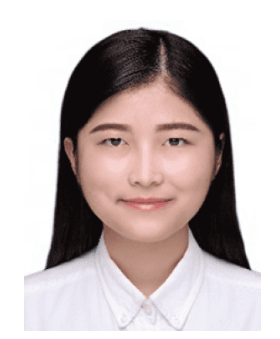

Heng Wang received her BSc degree from $\mathrm{Wu}$ han University of Science and Technology in 2018. She currently studies as a master candidate under the supervision of Prof. Jingyu Wang at Huazhong University of Science and Technology. Her research mainly focuses on the assembly strategy and formation mechanism of composite nanostructures for photocatalysis.

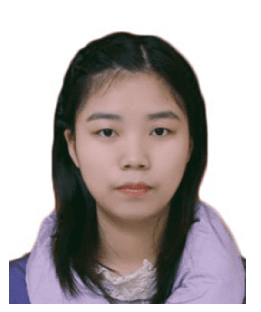

Qian Tang received her BSc degree from Wuhan University of Science and Technology in 2019. She is currently studying for a master's degree under the supervision of Prof. Jingyu Wang at Huazhong University of Science and Technology. Her main research interest focuses on the design and construction of porous frameworks for $\mathrm{CO}_{2}$ uptake and photocatalytic conversion.

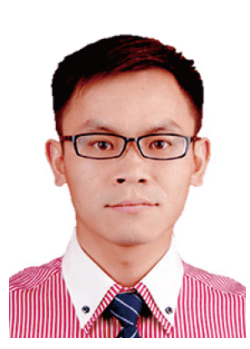

Zhen Chen obtained his $\mathrm{PhD}$ degree in materials physics and chemistry from Huazhong University of Science and Technology in 2018. Currently, he worked as a postdoctoral fellow under the supervision of Prof. Tao Li at Huazhong University of Science and Technology. His research interest focuses on the heterogeneous catalysis, mainly on the relationship between nanostructure and catalytic activity.

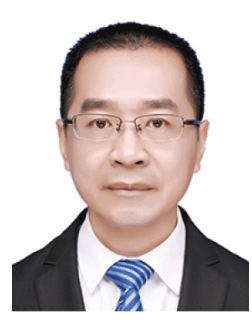

Tao Li received his $\mathrm{PhD}$ degree in chemistry from Dalian Institute of Chemical Physics, Chinese Academy of Sciences in 1998 and then worked as a research staff at this institute until 2000. Thereafter, he worked as a postdoctoral fellow at Taiwan University (2000-2002). He spent two years as a special researcher at the National Institute of Advanced Industrial Science and Technology (AIST), Japan. In 2004, he joined Huazhong University of Science and Technology as a professor. His research interest mainly focuses on the environmental heterogeneous catalysis.

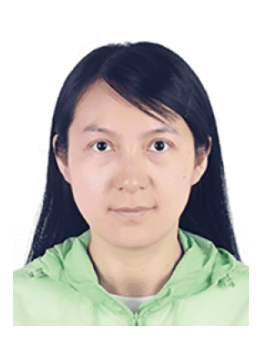

Jingyu Wang is a professor in the School of Chemistry and Chemical Engineering, Huazhong University of Science and Technology. Prior to that, she worked as an associate professor at Harbin Institute of Technology and a visiting scholar at the University of Chicago. She received her PhD degree in chemistry from Wuhan University in 2007. Her current research interest includes the development of photocatalysts for environmental and energy applications.

\section{光催化中二氧化硅基纳米结构的研究进展}

\section{王蘅, 唐倩, 陈真, 李涛, 王靖宇*}

摘要 由于太阳能转化效率对资源开发和环境净化应用的重要影 响, 发展高效光催化剂成为一个研究热点. 光催化性能主要取决于 材料的光吸收、电荷产生与分离、表面性质以及结构稳定性等特 性. 多孔二氧化硅因具有高比表面积、孔隙可调和表面易修饰等 独特优势, 而发展为一个用于构建结构明晰的纳米结构(如核-壳、

蛋黄-壳和其他特殊结构)的重要平台, 以有效改善上述决定光催化 性能的一种或多种特性. 通常, 中空的结构有利于光散射和比表面 积的增加, 而二氧化硅作为包覆或粘结材料可对光催化剂表面改 性以增强其对反应物的表面吸附和物理化学稳定性. 本文综述了 结构明晰二氧化硅基纳米结构的设计、合成、形成机理以及对光 催化性能调控等方面的最新研究进展. 